ENGINEERING DATA TRANSMITTAL

\begin{tabular}{|c|c|c|c|c|c|c|c|c|}
\hline \multicolumn{3}{|c|}{$\begin{array}{l}\text { 2. To: (Receiving Organization) } \\
\text { Distribution }\end{array}$} & \multicolumn{2}{|c|}{$\begin{array}{l}\text { 3. From: (Originating Organization) } \\
\text { Nuclear Safety }\end{array}$} & \multicolumn{4}{|c|}{$\begin{array}{r}\text { 4. Related EDT No.: } \\
\qquad \text { N/A }\end{array}$} \\
\hline \multicolumn{3}{|c|}{$\begin{array}{l}\text { 5. Proj/Prog/Dept/Div.: } \\
\text { Spent Nuclear Fuel }\end{array}$} & \multicolumn{2}{|c|}{$\begin{array}{l}\text { 6. Design Authority/Design Agent/Cog. Engr.: } \\
\text { Y. J. Liu }\end{array}$} & \multicolumn{4}{|c|}{$\begin{array}{r}\text { 7. Purchase Order No.: } \\
\qquad N / A\end{array}$} \\
\hline \multicolumn{5}{|c|}{ 8. Originator Remarks: } & \multicolumn{4}{|c|}{$\begin{array}{r}\text { 9. Equip./Component No.: } \\
\text { N/A }\end{array}$} \\
\hline \multicolumn{3}{|c|}{ For approval and release. } & & \multicolumn{4}{|c|}{$\begin{array}{l}\text { 10. System/Bldg.Facility: } \\
\qquad \text { W } 741 \text {. } 379 \text { कst }\end{array}$} \\
\hline \multirow{3}{*}{\multicolumn{3}{|c|}{ 11. Recejver Remarks: }} & \multirow{3}{*}{\multicolumn{2}{|c|}{ Document? [] Yes $[\mathrm{x}]$ No }} & \multicolumn{4}{|c|}{$\begin{array}{r}\text { 12. Major Assm. Dwg. No.: } \\
\text { N/A }\end{array}$} \\
\hline & & & & & \multicolumn{4}{|c|}{$\begin{array}{l}\text { 13. Permit/Permit Application No.: } \\
\text { N/A }\end{array}$} \\
\hline & & & & & \multicolumn{4}{|c|}{$\begin{array}{l}\text { 14. Required Response Date: } \\
\text { N/A }\end{array}$} \\
\hline 15. & & DAT & TRANSMI & & (F) & (G) & (H) & (I) \\
\hline $\begin{array}{l}(A) \\
\text { tem } \\
\text { No. } \\
\text { No. }\end{array}$ & (B) Documentiorawing No. & $\begin{array}{l}\text { (C) } \\
\text { sheet } \\
\text { No. }\end{array}$ & $\begin{array}{l}\text { (o) } \\
\text { Rev. } \\
\text { No. }\end{array}$ & (E) Title or Description of Data Transmitted & $\begin{array}{l}\text { Approval } \\
\text { Desiginator }\end{array}$ & $\begin{array}{l}\text { Resoson } \\
\text { Sor Trans. } \\
\text { mittal }\end{array}$ & $\begin{array}{l}\text { Origi- } \\
\text { nator } \\
\text { Dispow } \\
\text { sition }\end{array}$ & $\begin{array}{c}\text { Rectiver } \\
\text { Disposition }\end{array}$ \\
\hline 1 & SNF-4042 & N/A & 0 & $\begin{array}{l}\text { Evaluation of Accident } \\
\text { Frequencies at the Canister } \\
\text { Storage Building }\end{array}$ & $S^{N}$ & 1,2 & I & 1 \\
\hline & & & & & & & & \\
\hline & & & & & & & & \\
\hline & & & & & & & & \\
\hline & & & & & & & & \\
\hline & & & & & & & & \\
\hline
\end{tabular}

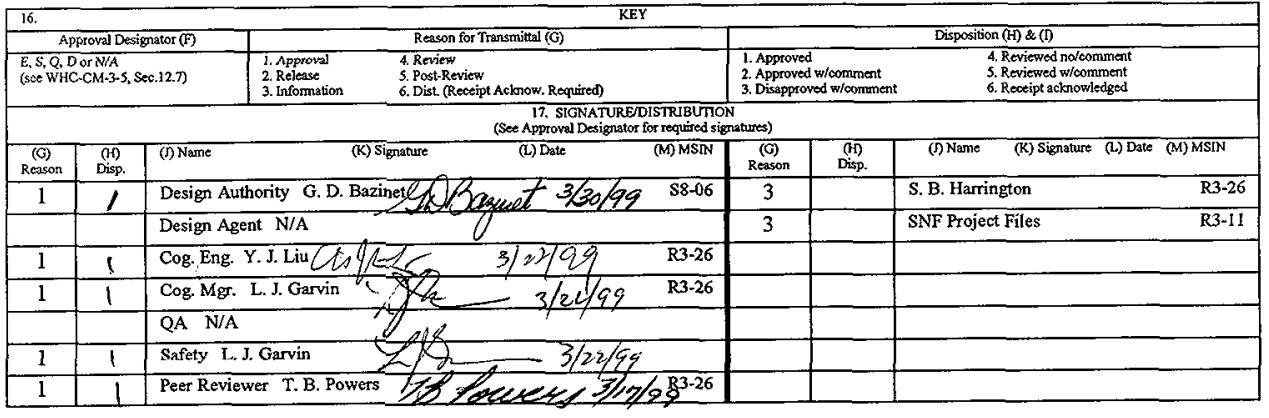

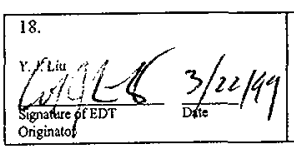

19.

Authorized Representative for Receiving Organization

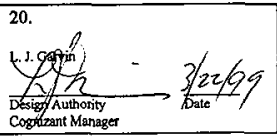

21. DOE APPROVAL (if required)

Ctrl. No.

[] Approved

[] Approved w/comments

[] Disapproved w/comments 


\title{
Evaluation of Accident Frequencies at the Canister Storage Building
}

\author{
Y. J. Liu \\ Duke Engineering \& Services Hanford, Richland, WA 99352 \\ U.S. Department of Energy Contract DE-AC06-96RL13200
}

EDT: 624298

Org Code: 2 F200

B\&R Code: EW31354040
UC: 920

Charge Code: 105625/BB20

Total Pages: 71

Key Words: Canister Storage Building, CSB, Design Basis Events, Accident Frequency, Fault Tree

Abstract: By using the fault tree logic, an evaluation of the design basis accident frequencies at the Canister Storage Building has been performed.

The evaluation demonstrates that due to low frequency of occurrences, the following design basis accidents are considered not credible (annual frequency of less than $10^{-6}$ ):

- Rearrangement of multi-canister overpack (MCO) internals

- Gaseous release from the MCO

- MCO internal hydrogen explosion

- MCO external hydrogen explosion

- Thermal nuaway reactions inside the MCO

- Violation of design temperature criteria

TRADEMARK DISCLAIMER. Reference herein to any specific commercial product, process, or service by trade name, trademark, manufacturer, or otherwise, does not necessarily constitute or imply its endorsement, recommendation, or favoring by the United States Government or any agency thereof or its contractors or subcontractors.

Printed in the United States of America. To obtain copies of this document, contact: Document Control Services, P.O. Box 950, Mailstop H6-08, Richland WA 99352, Phone (509) 372-2420; Fax (509) 376-4989.
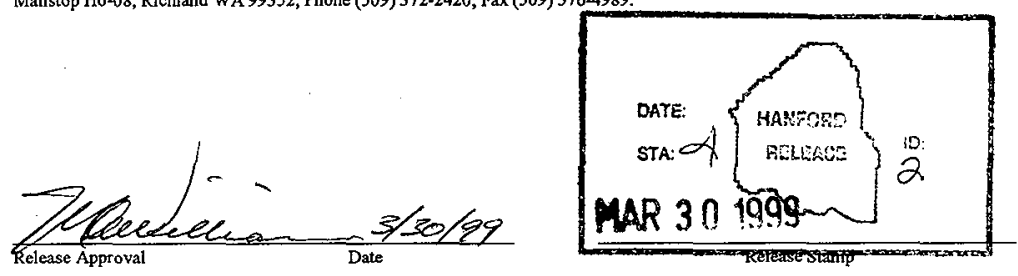

\section{Approved for Public Release}


SNF-4042 REV 0

\section{EVALUATION OF ACCIDENT FREQUENCIES AT}

\section{THE CANISTER STORAGE BUILDING}

March 1999 
SNF-4042 REV 0

This page intentionally left blank. 


\section{CONTENTS}

1.0 EVALUATION OF ACCIDENT FREQUENCIES AT THE CANISTER

STORAGE BUILDING

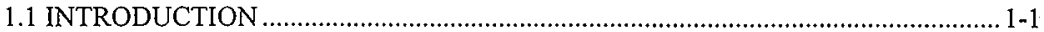

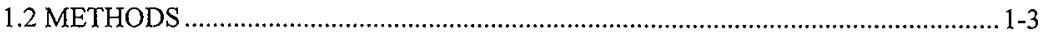

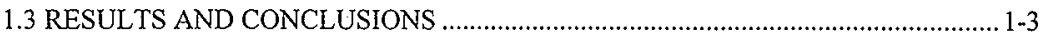

2.0 FREQUENCY OF A SHEAR OF A MULTI-CANISTER OVERPACK BY

THE MULTI-CANISTER OVERPACK HANDLING MACHINE AT

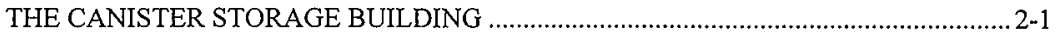

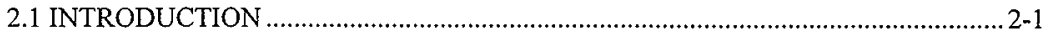

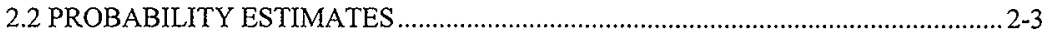

2.2.1 Multi-Canister Overpack Shear Due to Turret Rotation..........................................2-3

2.2.2 Multi-Canister Overpack Shear Due to Lateral Movement................................2-8

2.2.3 Top Event ............................................................................................. 2-12

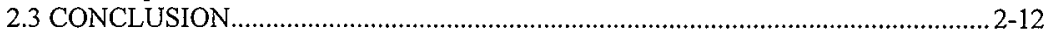

3.0 FREQUENCY OF A MULTI-CANISTER OVERPACK DROP FROM THE

MULTI-CANISTER OVERPACK HANDLING MACHINE ............................................. 3-1

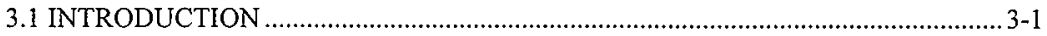

3.1.1 Probability of Structural Failure of Multi-Canister Overpack

Handling Machine Mechanical Components.........................................................3-1

3.1.2 Probability of Failure of Multi-Canister Overpack Handling Machine

Safety Interlocks ................................................................................................ 3-2

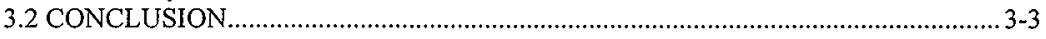

4.0 FREQUENCY OF OVERPRESSURIZATION OF THE MULTI-CANISTER

OVERPACK BY THE INERT GAS SYSTEM ……........................................................4-1

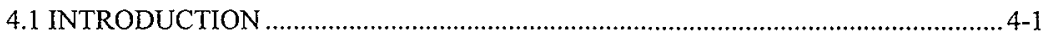

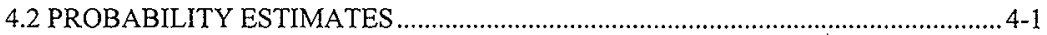

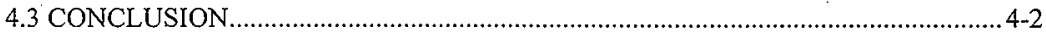

5.0 FREQUENCY OF A GASEOUS RELEASE RESULTING FROM A LEAK

IN THE MULTI-CANISTER OVERPACK SAMPLING SYSTEM AT

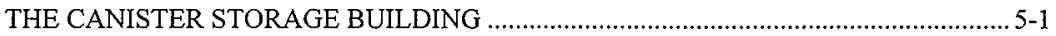

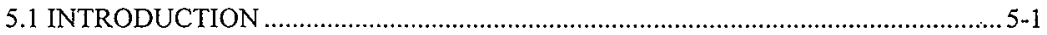

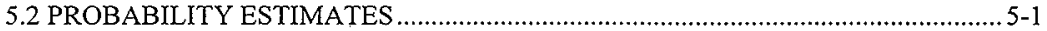

5.2.1 Multi-Canister Overpack Leak ........................................................................ 5-2

5.2.2 Loss of Filtered Ventilation in the Sampling Hood .............................................5-3

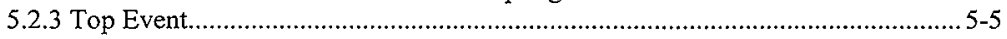

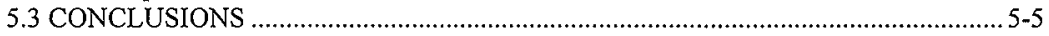

6.0 FREQUENCY OF MULTI-CANISTER OVERPACK INTERNAL EXPLOSION

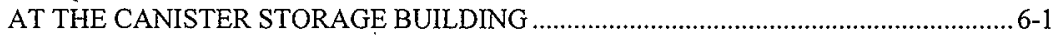

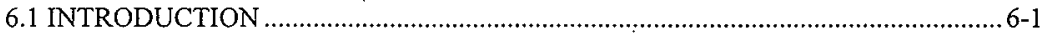

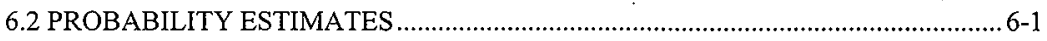

6.3 CONCLUSION.................................................................................................

7.0 FREQUENCY OF MULTI-CANISTER OVERPACK EXTERNAL EXPLOSION

AT THE CANISTER STORAGE BUILDING ...........................................................

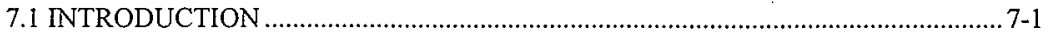




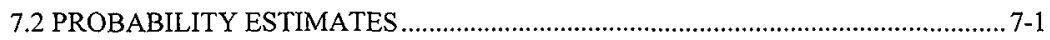

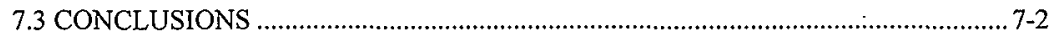

8.0 FREQUENCY OF THERMAL RUNAWAY ACCIDENT IN A MULTI-

CANISTER OVERPACK AT THE CANISTER STORAGE BUILDING ......................... 8-1

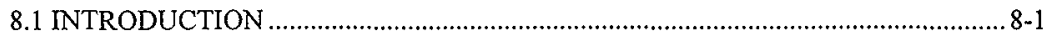

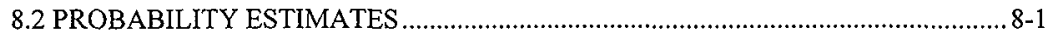

8.2.1 Thermal Runaway Caused by Reaction with Air .................................................... 8-2

8.2.2 Thermal Runaway Caused by Reaction with Water............................................ 8-3

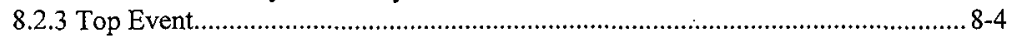

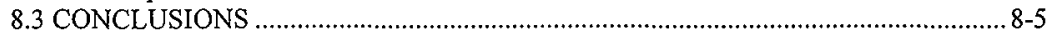

9.0 FREQUENCY OF VIOLATION OF DESIGN TEMPERATURE CRITERIA ….............9-1

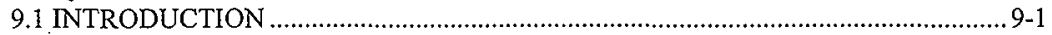

9.2 PROBABILITY ESTIMATES ................................................................................ 9-1

9.2.1 Loss of Active Cooling in Sampling/Weld Station Pit .......................................... 9-1

9.2.2 Loss of Passive Cooling in Vault....................................................................... 9-2

9.2.3 Top Event....................................................................................................... 9-3

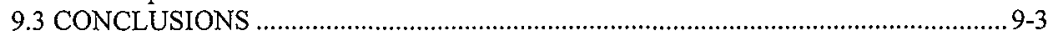

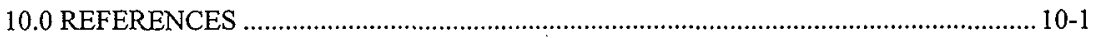

11.0 PEER REVIEW CHECKLIST .............................................................................. 11 


\section{LIST OF FIGURES}

Figure 1. Fault Tree for a Shear of a Multi-Canister Overpack by the Multi-Canister Overpack Handling Machine at the Canister Storage Building

Figure 2. Fault Tree for Overpressurization of the Multi-Canister Overpack by the Inert Gas System.

Figure 3. Fault Tree for a Gaseous Release Resulting from a Leak in the Multi-Canister Overpack Sampling System at the Canister Storage Building.

Figure 4. Fault Tree for a Multi-Canister Overpack Internal Explosion at the Canister Storage Building.

Figure 5. Fault Tree for a Multi-Canister Overpack External Explosion at the Canister Storage Building.

Figure 6. Fault Tree for a Thermal Runaway Accident in a Multi-Canister Overpack at the Canister Storage Building.

Figure 7. Fault Tree for Violation of Design Temperature Criteria. 


\section{SNF-4042 REV 0}

\section{LIST OF TERMS}

CSB Canister Storage Building

FSAR final safety analysis report

HEPA high-efficiency particulate air (filter)

HVAC heating, ventilation, and air conditioning

MCO multi-canister overpack

MHM multi-canister overpack handling machine

TSR technical safety requirement 


\subsection{EVALUATION OF ACCIDENT FREQUENCIES AT THE CANISTER STORAGE BUILDING}

\subsection{INTRODUCTION}

This report presents an evaluation of the design basis accident frequencies at the Canister Storage Building (CSB). The design basis accident analyses form a safety basis for the final safety analysis report and present a comprehensive evaluation of the CSB handling- and storagerelated activities and natural phenomena and external hazards that can affect the public, workers, and the environment. Single and multiple initiating events from equipment and human error failures in the facility have been considered.

The hazard identification and evaluation process provided a thorough, predominately qualitative, evaluation of the spectrum of risks to the public, workers, and the environment (HNF-SD-SNF-HIE-001). This process resulted in the selection of six candidate accidents for more comprehensive analysis in the CSB final safety analysis report (FSAR) (HNF-3553, Annex A). The six design basis accidents were selected to ensure that the range of accident scenarios analyzed in the accident analysis represented a complete set of representative and bounding conditions. A summary of the six design basis accidents documented in the CSB FSAR is presented below. The frequency of each of the six accidents is evaluated and estimated in this report.

- Rearrangement of multi-canister overpack (MCO) internals

Two scenarios have been identified for this accident category. The first scenario describes a physical shear force applied to the $\mathrm{MCO}$ by the MCO handling machine (MHM) such that containment of the fuel is breached and criticality geometry control is lost. The second scenario is a drop of MCO from the MHM such that containment of the fuel is breached and criticality geometry control is lost. The safety-class features selected for this event include MHM seismic restraints and MHM interlocks that ensure that the seismic restraints are applied and that the MHM trolley, bridge, and turret drives cannot operate when the MCO is in a position where it could be subjected to a rotational or lateral force. The MHM interlocks and restraints combine to prevent the shear and the drop of an MCO. Section 2.0 presents the evaluation of the frequency of a shear of an MCO by the MHM. Section 3.0 presents the evaluation of the frequency of an MCO drop by the MHM.

- Gaseous release from the MCO

Two scenarios have been identified for this accident category. The first accident scenario describes the overpressurization of the $\mathrm{MCO}$ by the inert gas system during the reinerting of a monitored $\mathrm{MCO}$ after sampling. Violation of the design pressure of the MCO could lead to criticality geometry control violations and thus requires safety-class controls to prevent this accident. Safety-class features required to prevent this accident are redundant pressure safety valves on the inert gas system lines. These prevent the purge gas from pressurizing the $\mathrm{MCO}$ above its design 
pressure. Section 4.0 presents the evaluation of the frequency of overpressurization of the MCO by the inert gas system.

The second scenario involves a release of entrained particulate from a pressurized leak of gas from an $\mathrm{MCO}$ at the sampling/weld station. Safety-significant features selected for this event include the sample hood and exhaust system, an exhaust flowindicating device, pressure tests to verify the sample connection to the $\mathrm{MCO}$ before opening the MCO port valve, and the MHM collision avoidance system (interlock P10) and associated sensors and switches. Section 5.0 presents the evaluation of the frequency of MCO gaseous release resulting from a leak in the MCO sampling system.

- MCO internal hydrogen explosion

The bounding scenario for this accident category describes the ignition and explosion of a hydrogen-oxygen mixture inside an MCO when purge gas contaminated with oxygen is used to inert the $\mathrm{MCO}$ after sampling. A technical safety requirement (TSR) has been identified for verification of helium purity by the supplier's shipping papers or from a sample. Section 6.0 presents the evaluation of the frequency of an MCO internal explosion.

- MCO external hydrogen explosion

The bounding scenario for this accident category describes the release of hydrogen from an MCO into the sample hood and exhaust system. The hydrogen gas, after mixing with air, ignites and explodes. Safety-significant features selected to prevent this event include the sampling line and connection, the sample hood and exhaust system, verification of a minimum flow rate through the exhaust system, verification of the sample line connection, and pressure testing of the sample line before opening the MCO port valve. Section 7.0 presents the evaluation of the frequency of $\mathrm{MCO}$ external explosion.

- Thermal runaway reactions inside the $\mathrm{MCO}$

Three scenarios have been identified for this accident category. The first scenario describes an accident in which the MCO is left in the sampling/weld station for at least 50 days. The analysis in the CSB FSAR shows an increase in MCO temperatures but also shows MCO pressure remain within design limits (HNF-3553, Annex A).

The second scenario describes an accident initiated by inadvertently filling an MCO with oxygen at the sampling/weld station. For this scenario, the unmitigated consequences will not violate the safety limit on $\mathrm{MCO}$ pressure or violate criticality controls (HNF-3553, Annex A).

The third scenario involves an accident at the sampling/weld station in which the $\mathrm{MCO}$ is completely sheared, with the total MCO cross section exposed to the 
atmosphere and $\mathrm{MCO}$ wall temperatures greater than $100^{\circ} \mathrm{C}$. This scenario is analyzed to illustrate the consequences of a thermal excursion. Section 8.0 presents the evaluation of the frequency of thermal runaway accident in the $\mathrm{MCO}$.

- Violation of design temperature criteria

The bounding scenarios for this accident category describe conditions in which the MCO or CSB safety-class concrete structures could exceed their design temperatures because of a lack of adequate cooling. There are two scenarios considered. The first scenario is an MCO left in the sampling/weld station without active glycol cooling and the second is the thermal heatup at the vault caused by a loss of inlet air flow in the inlet stack. Safety-class features selected for this event include the CSB vault, inlet and exhaust structures, and controls for maintaining an acceptable $\mathrm{MCO}$ temperature at the sampling/weld station. For the first scenario, glycol or forced-air cooling to the MCO would be initiated. For the second scenario, any debris would be removed from the air intake and exhaust structures to restore air flow through the vault. Section 9.0 presents the evaluation of the frequency of violation of design temperature criteria.

\subsection{METHODS}

To assess the likelihood of each design basis accident at the CSB, logic diagrams, in fault tree format, were constructed. These diagrams show all possible ways that the accidents could occur as a result of a combination of operation error and component failure. In the fault trees, each box with a circle underneath represents a failure that could contribute to a potential accident at the CSB. The failures are combined through logic gates, either AND gates (flat bottom, semicircle top) or OR gates (arched bottom and arrow head top). An AND gate requires all inputs to the gate (from below) to occur in order for the result, described in the box above the gate, to occur. An OR gate only requires that any one input to the gate (from below) occur in order for the result, described in the box above the gate, to occur. Final estimates of the total likelihood of an accident resulting from component failure and operation error are obtained by properly combining the probabilities of each branch of the diagram according to Boolean algebra.

The bases of the probability estimates for initiating events are primarily from EGG-SSRE-8875, Generic Component Failure Data Base for Light Water and Liquid Sodium Reactor PRAs, and DP-1633, Component Failure-Rate Data with Potential Applicability to a Nuclear Fuel Reprocessing Plant. The bases of the probability estimates for human error are primarily from NUREG/CR-4772, Accident Sequence Evaluation Program Human Reliability Analysis Procedure.

\subsection{RESULTS AND CONCLUSIONS}

Results and conclusions for each design basis accident are summarized below. 
- Rearrangement of MCO internals

The internal arrangement of the MCO might be impacted either by a shear force applied to the MCO by the MHM or by a drop from the MHM. The frequency of a shear of an MCO by the MHM is conservatively estimated to be $1.28 \times 10^{-7}$. The shear event is considered incredible as long as effective operations and good maintenance and testing programs are applied. The MHM design is robust against both mechanical and structural failures and against electrical interlock failures. The failure frequency analysis shows that the total expected $\mathrm{MCO}$ drop frequency from structural and interlock failures places these events in a range of $1.0 \times 10^{-8}$, which is considered not credible. It is recommended that a systematic and periodic interlock maintenance and calibration routine be in place to ensure that the interlock system will not be defeated in a way that could lead to the drop of an MCO.

- Gaseous release from the MCO

The first accident scenario describes the overpressurization of the $\mathrm{MCO}$ by the inert gas system during the reinerting of a monitored $\mathrm{MCO}$ after sampling. The frequency of overpressurization of an $\mathrm{MCO}$ by the inert gas system is estimated to be in the order of $1.0 \times 10^{-10}$ because there are two safety-class safety valves on the inert gas system lines to prevent this accident. Therefore, the event is not credible.

The second scenario involves a release of entrained particulate from a pressurized leak of gas from MCO at the sampling/weld station. If $24 \mathrm{MCO}$ samples are performed every year, the frequency would be in the range of $2.88 \times 10^{-7}$.

- MCO internal hydrogen explosion

This study demonstrates that the MCO internal explosion accident at CSB is an incredible event with an estimated annual frequency of $1.22 \times 10^{-8}$. This is because there is a TSR in place to ensure that the helium received at CSB for use in the inert gas system must be tested for purity.

- MCO external hydrogen explosion

This study shows that the MCO external explosion accident is an incredible event with an estimated annual frequency of $5.71 \times 10^{-7}$. However, the measures and controls identified (see Section 5.0) for preventing gaseous releases during sampling should be implemented prior to and during the MCO sampling operation.

- Thermal runaway reactions inside the MCO

This study demonstrates that the thermal runaway accident is considered as an incredible event with an estimated annual frequency of $8.45 \times 10-10$. The followings are the major reasons why the accident is incredible.

- First, there is not sufficient water to produce a continuing reaction. 
- Second, it is highly unlikely that the cooling at the sampling/weld station will not be restored within 50 days after loss of cooling.

- Third, the MCO will not stay at the sampling/weld station for more than 50 days.

- Fourth, a complete shear of the MCO is an incredible event.

- Violation of design temperature criteria

Based on the frequency evaluation, it is concluded that the event that has the potential of violating the MCO temperature design criteria is incredible. The annual frequency is estimated to $3.0 \times 10^{-7}$. This is because that it is extremely unlikely that the cooling at the sampling/weld station will be lost for more than 50 days or that the vault intake and exhaust path is significantly obstructed. 
SNF-4042 REV 0

This page intentionally left blank. 


\subsection{FREQUENCY OF A SHEAR OF A MULTI-CANISTER OVERPACK BY THE MULTI-CANISTER OVERPACK HANDLING MACHINE AT THE CANISTER STORAGE BUILDING}

\subsection{INTRODUCTION}

A shear of an MCO by the MHM was identified in the CSB hazard analysis as a potentially significant accident (HNF-SD-SNF-HIE-001). The rotational and lateral movements of the MHM turret provide the mechanism for applying shear forces to the side of the MCO. These shear forces could be applied whenever the MCO extends across two regions that may rotate with respect to one another, such as when the MCO is partially lowered through the CSB deck into a storage tube or when the MCO is partially lowered below the MHM turret-base interface.

Because this accident has the potential to cause the most damage to an MCO in terms of its fuel confinement and containment safety functions, it is considered to bound the consequences of all other accidents that could rearrange the $\mathrm{MCO}$ internals. Simple analysis has not been able to demonstrate that it is not possible for the turret to shear the MCO. However, turret rotation and lateral movement cannot occur while the $\mathrm{MCO}$ is between regions unless safety class MHM interlocks are defeated.

This study estimates the frequency of an MCO shear caused by turret rotation and MHM lateral movement. Turret rotation could be caused by either operating errors coincident with defeated interlocks or a seismic event coincident with defeated interlocks. Likewise, MHM lateral movement could be caused by operating errors coincident with defeated interlocks.

The MHM interlocks have been designed as either dual- or single-channel interlocks, depending upon their designated importance to nuclear and radiological safety. Dual-channel interlocks (Hazard N Class) have two independent sensor, electrical relay, and power contactor paths (X-channel and $Y$-channel) that must provide permission for the associated MHM drives to have power available upon operator demand. Single-channel interlocks (Hazard P Class) have a single sensor, electrical relay, and power contactor path (X-channel) that must provide permission for the associated MHM drives to have power available upon operator demand. The interlocks listed below inhibit or limit turret rotation and lateral movement unless certain conditions are met.

- Interlock P3 inhibits bridge travel, release of bridge seismic clamps, trolley travel, and retraction of trolley restraint jacks unless the shield skirt is fully retracted. P3 is explicitly included in the fault tree logic.

- Interlock P4 inhibits bridge travel unless all bridge seismic clamps are fully released. P4 is classified as Hazard P Class that has only one channel (X-Channel). P4 is explicitly included in the fault tree logic.

- Interlock P6 inhibits turret rotation, turret locking pin disengagement, and base locking pin disengagement unless (1) the MHM is in MCO mode or impact absorber 
exchange mode and the MCO grapple is at upper datum, or (2) the MHM is in tube plug exchange mode and the MCO hoist is at the tube plug raise limit. P6 is explicitly included in the fault tree logic.

- Interlock P7 inhibits turret rotation, turret locking pin disengagement, and base locking pin disengagement unless the tube plug hoist is fully raised. This is when the MHM is in the tube plug exchange mode. The P7 interlock is not included in the fault tree logic because if the P8O interlock were defeated, it would be possible to rotate the turret while the $\mathrm{MCO}$ was between regions regardless of whether or not the P7 interlock was defeated.

- Interlock P80 The P80 interlock inhibits change of operating mode unless the MHM is located at the exchange facility, the plug cask is empty, the MCO cask is empty, and the shield skirt is fully seated. Only if the P80 interlock were defeated, would it be possible for the MCO hoist to raise the MCO when the MHM was in the tube plug exchange mode. If the P80 interlock were defeated, it would be possible to rotate the turret while the MCO was between regions. The P80 interlock is explicitly included in the fault tree logic.

- Interlock P9 inhibits crane bridge travel, crane trolley travel, shield skirt jack raising, tube plug hoist operation, and MCO hoist operation unless the base and turret locking pins are both fully engaged. If the P9 interlock were defeated, shear of an $\mathrm{MCO}$ due to turret rotation might be possible following a seismic event. P9 is explicitly included in the fault tree logic.

- Interlock P13 inhibits trolley travel unless the trolley seismic locking pins are fully retracted and the trolley locking jacks are fully retracted. P13 is classified as Hazard P Class that has only one channel (X-Channel). P13 is explicitly included in the fault tree logic.

- Interlock P21 inhibits shield skirt jack lowering, turret rotation, turret locking pin disengagement, base locking pin disengagement, tube plug hoist operation, and $\mathrm{MCO}$ hoist operation unless the crane seismic clamps are all fully applied. P21 is explicitly included in the fault tree logic.

- Interlock P24 inhibits the turret from rotating beyond its normal rotation limits. This interlock would have no impact on the frequency study, therefore it is not part of the fault tree.

- Interlock P25 inhibits turret rotation unless the turret and base locking pins are both fully disengaged. P25 was conservatively assumed nonexistent in this study.

- Interlock P26 inhibits turret rotation, turret locking pin disengagement, base locking pin disengagement, tube plug hoist operation, and MCO hoist operation unless the shield skirt is fully seated. P26 was conservatively assumed nonexistent in this study. 


\subsection{PROBABILITY ESTIMATES}

A logic diagram, in fault tree format, was constructed (Figure 1) to assess the likelihood of an MCO shear by the MHM as a result of operating errors or failure of MHM interlocks to perform their function. Each box with a circle underneath represents a failure that could contribute to a potential MCO shear. The failures are combined through logic gates: AND gates (flat bottom, semicircle top) or OR gates (arched bottom and arrowhead top). An AND gate requires all inputs to the gate (from below) to occur for the result, described in the box above the gate, to occur. An OR gate only requires that any one input to the gate (from below) occur for the result, described in the box above the gate, to occur. Final estimates of the total likelihood of an $\mathrm{MCO}$ shear resulting from operating error or interlock failure are obtained by properly combining the probabilities of each branch of the diagram according to Boolean algebra. The following text describes each event for each path of the logic fault tree. The descriptions include estimates used in the current analysis of the probability for each event to occur.

\subsubsection{Multi-Canister Overpack Shear Due to Turret Rotation}

\subsubsection{Defeat of Interlock P6}

Failure Events S621 and S511. A mechanical limit switch will close a contactor in the $\mathrm{X}$-channel of interlock P6 when the MCO grapple is at the upper datum. This failure event means that the contactor is closed because of a failure of the limit switch even though an MCO is not at the upper datum. The X-channel is defeated if the contactor is closed. Failure event S511 is the defeat of the X-channel of interlock P6. The rate for spurious operation of limit switches is $1.0 \times 10^{-6}$ per hour. The corresponding annual failure probability of the limit switch is $\left(1.0 \times 10^{-6}\right) \times 8,760 \mathrm{~h} /$ year $=8.76 \times 10^{-3}($ EGG-SSRE-8875) .

Failure Events $\mathbf{S 6 2 2}$ and $\mathbf{S 5 1 2}$. A resolver mounted on the MCO hoist provides input to a preprogrammed logic device that indicates whether the $\mathrm{MCO}$ grapple is at the upper limit. A failure of the device will cause a contact to close in Y-channel of interlock P6. In this analysis, the upper limit is treated the same as the upper datum. This failure event means that the contactor is closed because of a failure of the resolver even though an $\mathrm{MCO}$ is not at the upper datum. The $\mathrm{X}$-channel is defeated if the contactor is closed. A resolver is a programmable limit switch without moving electrical contacts, appreciable wear, or drift. Because of a lack of resolver failure data, the failure rate for a small motor or servo is used. The failure rate of small motors or servos is in the range of $3.0 \times 10^{-7}$ per hour (DP-1633), which is an annual failure probability of $2.63 \times 10^{-3}$. Failure Event $\mathrm{S} 512$ is the defeat of the Y-channel of interlock P6. An increase of a factor of ten is assumed in order to account for possible common mode effects (i.e., $2.63 \times 10^{-2}$ ).

Failure Event S411. If both the X-and Y-channels are defeated, the P6 interlock is defeated. Combining the probabilities of failure of both the $\mathrm{X}$ - and $\mathrm{Y}$-channels yields a probability of $\left(8.76 \times 10^{-3}\right) \times\left(2.63 \times 10^{-2}\right)=2.30 \times 10^{-4}$ that the P6 interlock is defeated. 
Failure Event S302. It is assumed that once the P6 interlock is defeated, the turret will rotate. The annual failure probability of interlock P6 is therefore the same as the failure probability of $\$ 411$, which is $2.30 \times 10^{-4}$.

\subsubsection{Defeat of Interlock P80}

Failure Event S601. Failure of the limit switch that indicates the bridge location causes a contactor in the X-channel of interlock P80 to close even though both the bridge and the trolley are not within the exchange facility zone. The probability of the limit switch operating spuriously is conservatively assumed to be $8.76 \times 10^{-3}$ (EGG-SSRE-8875).

Failure Event S602. The tube-plug-hoist-fully-raised limit switch is positioned near the top of the tube plug hoist screw jack bellows assembly and directly contact the top of the hoist when activated. The tube plug hoist should be fully raised (to activate the limit switch) and then lowered $2 \mathrm{~cm}$ to $3 \mathrm{~cm}$ and the signal from this switch checked to confirm that the switch does not continue to indicate that the tube plug hoist is raised. A spurious operation of the limit switch will cause a contactor in the X-channel of interlock P80 to close even though the tube plug grapple is not fully raised. The probability of the limit switch operating spuriously is conservatively assumed to be $8.76 \times 10^{-3}$ (EGG-SSRE-8875). If we presume that the common mode effects, if any, increase the probability of failure by a factor of ten, the probability of a limit switch failure is $8.76 \times 10^{-2}$.

Failure Event S603. The tube-plug-jaws-fully-open limit switch detects when the cam that opens and closes the jaws has rotated to the position range corresponding to the jaws being fully open. It is assumed that a spurious operation of the limit switch will cause a contactor in the X-channel of interlock P80 to close even though the tube plug jaws are not open. In MCO mode, the jaws are not open. The probability of the limit switch operating spuriously is assumed to be $8.76 \times 10^{-3}$ (EGG-SSRE-8875). To be conservative, the probability of failure is increased by a factor of 100 to account for minor interactions or common cause links, if any. Therefore, the probability is $8.76 \times 10^{-1}$.

Failure Event S604. The plug-cask-empty photoelectric switch indicates whether or not a tube plug is in the tube plug cavity. It is assumed that a spurious operation of the limit switch will cause a contactor in the X-channel of interlock P80 to close even though the tube plug cask is not empty. The probability of the limit switch operating spuriously is assumed to be $8.76 \times 10^{-3}$ (EGG-SSRE-8875). To be conservative, the probability of failure is increased by a factor of 100 to account for minor interactions or common cause links, if any. Therefore, the probability is $8.76 \times 10^{-1}$.

Failure Event S605. The MCO-grapple-jaws-not-closed limit switch indicates that the jaws are closed when the distance between the opposing grapple surfaces that contact the outer rim of the MCO lift feature (back of jaw recess) is $523.65 \mathrm{~mm}$. Failure of the limit switch causes a contactor in the X-channel of interlock P80 to close even though the MCO grapple jaws are closed. The probability of the limit switch operating spuriously is assumed to be $8.76 \times 10^{-3}$ (EGG-SSRE-8875). To be conservative, the probability of failure is increased by a factor of 100 to account for minor interactions or common cause links, if any. Therefore, the probability is 
$8.76 \times 10^{-1}$.Failure Event S606. The MCO-grapple-not-in-contact-with-a-load limit switch is set so that the grapple proximity probe must be essentially fully extended for no contact to be sensed. It is assumed that a failure of the limit switch will cause a contactor in the X-channel of interlock P80 to close even though the MCO grapple is in contact with a load. The probability of the limit switch operating spuriously is assumed to be $8.76 \times 10^{-3}$ (EGG-SSRE-8875). To be conservative, the probability of failure is increased by a factor of 100 to account for minor interactions or common cause links, if any. Therefore, the probability is $8.76 \times 10^{-1}$.

Failure Event S501. The X-channel of interlock P80 is defeated if all the failure events from S601 through S606 are true. The shield skirt is assumed to be fully seated, and the contactor $\mathrm{P} 26 \mathrm{X}$ is in the closed position. Therefore, the probability of the contactor being closed is 1 . The probability of failure of the X-channel is the combined probability of failure events $\mathrm{S} 601, \mathrm{~S} 602, \mathrm{~S} 603, \mathrm{~S} 604, \mathrm{~S} 605$, and $\mathrm{S} 606$, a value of $\left(8.76 \times 10^{-3}\right) \times\left(8.76 \times 10^{-2}\right) \times\left(8.76 \times 10^{-1}\right)$ $\times\left(8.76 \times 10^{-1}\right) \times\left(8.76 \times 10^{-1}\right) \times\left(8.76 \times 10^{-1}\right)=4.52 \times 10^{-4}$.

Failure Event S611. Failure of the limit switch that indicates the bridge location causes a contactor in the Y-channel of interlock P80 to close even though both the bridge and the trolley are not within the exchange facility zone. The probability of the limit switch operating spuriously is conservatively assumed to be $8.76 \times 10^{-3}$ (EGG-SSRE-8875).

Failure Event S612. The tube-plug-hoist-fully-raised limit switch is positioned near the top of the tube plug hoist screw jack bellows assembly and directly contacts the top of the hoist when activated. The tube plug hoist should be fully raised (to activate the limit switch) and then lowered $2 \mathrm{~cm}$ to $3 \mathrm{~cm}$ and the signal from this switch checked to confirm that the switch does not continue to indicate that the tube plug hoist is raised. A spurious operation of the limit switch will cause a contactor in the Y-channel of interlock P80 to close even though the tube plug grapple is not fully raised. The probability of the limit switch operating spuriously is assumed to be $8.76 \times 10^{-3}$ (EGG-SSRE-8875). To be conservative, the probability of failure is increased by a factor of 10 to account for minor interactions or common cause links, if any. Therefore, the probability is $8.76 \times 10^{-2}$.

Failure Event S613. The tube-plug-jaws-fully-open limit switch detects when the cam that opens and closes the jaws has rotated to the position range corresponding to the jaws being fully open. It is assumed that a spurious operation of the limit switch will cause a contactor in the Y-channel of interlock P80 to close even though the tube plug jaws are not open. In MCO mode, the jaws are not open. The probability of the limit switch operating spuriously is assumed to be $8.76 \times 10^{-3}$ (EGG-SSRE-8875). To be conservative, the probability of failure is increased by a factor of 100 to account for minor interactions or common cause links, if any. Therefore, the probability is $8.76 \times 10^{-1}$.

Failure Event S614. The plug-cask-empty photoelectric switch indicates whether or not a tube plug is in the tube plug cavity. It is assumed that a spurious operation of the limit switch will cause a contactor in the $\mathrm{Y}$-channel of interlock P80 to close even though the tube plug cask is not empty. The probability of the limit switch operating spuriously is assumed to be $8.76 \times 10^{-3}$ (EGG-SSRE-8875). To be conservative, the probability of failure is increased by a 


\section{SNF-4042 REV 0}

factor of 100 to account for minor interactions or common cause links, if any. Therefore, the probability is $8.76 \times 10^{-1}$.

Failure Event S615. The MCO-grapple-jaws-not-closed limit switch indicates that the jaws are closed when the distance between the opposing grapple surfaces that contact the outer rim of the MCO lift feature (back of jaw recess) is $523.65 \mathrm{~mm}$. Failure of the limit switch causes a contactor in the Y-channel of interlock P80 to close even though the MCO grapple jaws are closed. The probability of the limit switch operating spuriously is assumed to be $8.76 \times 10^{-3}$ (EGG-SSRE-8875). To be conservative, the probability of failure is increased by a factor of 100 to account for minor interactions or common cause links, if any. Therefore, the probability is $8.76 \times 10^{-1}$.

Failure Event S616. The MCO-grapple-not-in-contact-with-a-load limit switch is set so that the grapple proximity probe must be essentially fully extended for no contact to be sensed. It is assumed that a failure of the limit switch will cause a contactor in the Y-channel of interlock P80 to close even though the MCO grapple is in contact with a load. The probability of the limit switch operating spuriously is assumed to be $8.76 \times 10^{-3}$ (EGG-SSRE-8875). To be conservative, the probability of failure is increased by a factor of 100 to account for minor interactions or common cause links, if any. Therefore, the probability is $8.76 \times 10^{-1}$.

Failure Event S502. The Y-channel of interlock P80 is defeated if all the failure events from $\$ 611$ through $\$ 616$ are true. The shield skirt is assumed to be fully seated, and the contact is in the closed position. The probability of failure of the $Y$-channel is the same as that for failure event $\mathrm{S} 501$ (i.e., $4.52 \times 10^{-4}$ ). A factor of 10 increase is conservatively assumed in order to account for possible common mode effects between two independent channels, resulting in a probability of failure of $4.52 \times 10^{-3}$.

Failure Event S401. If both the X-and Y-channels are defeated, interlock P80 is defeated. The failure probability is the combined probabilities of failure events $\mathrm{S} 501$ and $\mathrm{S} 502$, which yields a value of $\left(4.52 \times 10^{-4}\right) \times\left(4.52 \times 10^{-3}\right)=2.04 \times 10^{-6}$.

Failure Event $\mathbf{S 4 0 2}$. If the bridge and the trolley are not within the exchange facility zone, the operator should not make any mode changes. The probability that the operator will make a mode change is assumed to be $3.0 \times 10^{-2}$, which is a basic human error (NUREG/CR-4772).

Failure Event S301. If interlock P80 is defeated and the operator makes a mode change, it is assumed that the turret will rotate. The probability of both events occurring is $\left(2.04 \times 10^{-6}\right)$ $\times\left(3.0 \times 10^{-2}\right)=6.12 \times 10^{-8}$.

\subsubsection{Defeat of Interlock P9}

Failure Event $\mathbf{S 6 3 1}$. It is assumed that a failure of the proximity sensor that detects the engagement of the turret locking pin would cause a contactor in the X-channel of interlock P9 to close. This means that the sensor detects an engagement but, in fact, there is no engagement. 
The probability of failure of a sensor is in the range of $1.0 \times 10^{-6}$ per hour (EGG-SSRE-8875, DP-1633). A probability of $5.0 \times 10^{-6}$ per hour $\left(4.38 \times 10^{-2}\right)$ is assumed.

Failure Event $\mathbf{S 6 3 2}$. It is assumed that a failure of the proximity sensor that detects the engagement of the base locking pin would cause a contactor in the X-channel of interlock $\mathrm{P} 9$ to close. A factor of ten increase from the sensor failure rate was assumed in order to account for possible common mode effects (i.e., $4.38 \times 10^{-1}$ ).

Failure Event S521. If failure events S631 and S632 are both true, the X-channel of interlock P9 is defeated. The probability that the X-channel of interlock P9 is defeated is $1.92 \times 10^{-2}$.

Failure Event $\mathbf{S 6 3 5}$. It is assumed that a failure of the proximity sensor that detects the engagement of the turret locking pin would cause a contactor in the Y-Channel of interlock P9 to close. The probability of failure of the sensor is assumed to be the same as that of failure event $\mathrm{S} 631\left(4.38 \times 10^{-2}\right)$.

Failure Event $\mathbf{S 6 3 6}$. It is assumed that a failure of the proximity sensor that detects the engagement of the base locking pin would cause a contactor in the Y-channel of interlock P9 to close. The probability of failure of the sensor is assumed to be the same as that of failure event $S 632\left(4.38 \times 10^{-1}\right)$.

Failure Event S522. If failure events $\mathrm{S} 635$ and $\mathrm{S} 636$ are both true, the $\mathrm{Y}$-channel of interlock $\mathrm{P} 9$ is defeated. The probability of both failure events occurring is $1.92 \times 10^{-2}$. An increase of a factor of ten is assumed in order to account for common mode effects (i.e., $\left.1.92 \times 10^{-1}\right)$.

Failure Event S421. If both the X-and Y-channels are defeated, interlock P9 is defeated. The probability of the event is $\left(1.92 \times 10^{-2}\right) \times\left(1.92 \times 10^{-1}\right)=3.69 \times 10^{-3}$.

Failure Event S422. An earthquake occurs. The probability of a seismic event at the Hanford Site is in the range of $2.0 \times 10^{-4}$ per year (WHC-SD-W236A-TI-002).

Failure Event $\mathbf{S 3 0 3}$. If an earthquake occurs at the same time that interlock P9 is defeated, it is assumed that the turret will rotate because the turret locking pins are not fully engaged. The probability of this event is the combined probabilities of failure events $\mathrm{S} 421$ and S422, which is $\left(3.69 \times 10^{-3}\right) \times\left(2.0 \times 10^{-4}\right)=7.38 \times 10^{-7}$.

Failure Event S202. Failure event S301 (defeat of interlock P80)or S302 (defeat of interlock P6) or $\mathrm{S} 303$ (defeat of interlock P9) can cause the turret to rotate. The probability is the sum of the event probabilities for failure events $\mathrm{S} 301, \mathrm{~S} 302$, and $\mathrm{S} 303$, which yields a value of $\left(6.12 \times 10^{-8}\right)+\left(2.3 \times 10^{-4}\right)+\left(7.38 \times 10^{-7}\right)=2.3 \times 10^{-4}$.

Failure Event S201. The MCO shear can occur only if the MCO is between regions. The MCO hoist travels at a speed of around $5 \mathrm{ft} / \mathrm{min}$. For a $14-\mathrm{ft} \mathrm{MCO}$, the duration between regions should be no more than 5 minutes during normal MHM MCO hoist operation. Assuming that $200 \mathrm{MCO}$ are handled at the CSB per year and that the average number of MHM lifts per 
MCO per year is 5 , the total number of MHM lifts per year is 1,000 . The total duration MCOs are between regions in a year is estimated to be 87 hours. Therefore, the annual probability of an MCO being between regions is $1.0 \times 10^{-2}$.

Failure Event S203. The operator fails to recognize that the interlocks are malfunctioning. The basic human error probability of $3.0 \times 10^{-2}$ is assumed (NUREG/CR-4772).

Failure Event S101. The probability that the MCO will be sheared by rotation of the turret is the combined probability of failure events S201, S202, and S203. The probability is $\left(1.0 \times 10^{2}\right) \times\left(2.3 \times 10^{-4}\right) \times\left(3.0 \times 10^{-2}\right)=6.9 \times 10^{-8}$.

\subsubsection{Multi-Canister Overpack Shear Due to Lateral Movement}

\subsubsection{Defeat of the Interlock P3}

Failure Events S641and S531. It is assumed that a spurious operation of a limit switch will cause the X-channel of interlock $\mathrm{P} 3$ to be energized. Once it is energized, the X-channel of interlock $\mathrm{P} 3$ is defeated, even though the shield skirt is not fully retracted. The probability of the limit switch operating spuriously is conservatively assumed to be $8.76 \times 10^{-3}$ (EGG-SSRE-8875).

Failure Events S642 and S532. The Y-channel of interlock P3 has three limit switches. Assuming that all three fail, the Y-channel can be energized even though the shield skirt is not fully retracted. Once it is energized, the $\mathrm{Y}$-channel of interlock $\mathrm{P} 3$ is defeated. The probability of the limit switch operating spuriously is assumed to be $8.76 \times 10^{-3}$ (EGG-SSRE-8875). To be conservative, the probability of failure is increased by a factor of 10 for the second switch and by a factor of 100 for the third switch to account for minor interactions or common cause links, if any. Therefore, the probability of failure is $8.76 \times 10^{-2}$ for the second switch and $8.76 \times 10^{-1}$ for the third switch. The probability of a failure of all three switches is estimated to be $\left(8.76 \times 10^{-3}\right)$ $\times\left(8.76 \times 10^{-2}\right) \times\left(8.76 \times 10^{-1}\right)=6.72 \times 10^{-4}$, which takes into account the connective link between switches.

Failure Event S431. If both the $X$ - and $Y$-channels are defeated, interlock $P 3$ is defeated. Combining the probabilities of failure events S531 and S532, the probability of defeating interlock P3 is $5.89 \times 10^{-6}$.

\subsubsection{Defeat of Interlock P4}

Failure Event S651. There are four bridge seismic clamps on the east side of the CSB. Only if all bridge seismic clamps are fully released is bridge travel allowed. The probability of a limit switch operating spuriously is assumed to be $8.76 \times 10^{-3}$ (EGG-SSRE-8875). To be conservative, the probability of failure is increased by a factor of 10 for the second switch and by a factor of 100 for the third switch to account for minor interactions or common cause links, if any. Therefore, the probability of failure is $8.76 \times 10^{-2}$ for the second switch and $8.76 \times 10^{-1}$ for the third switch. The probability of a failure of all three switches is estimated to be $\left(8.76 \times 10^{-3}\right)$ $\times\left(8.76 \times 10^{-2}\right) \times\left(8.76 \times 10^{-1}\right)=6.72 \times 10^{-4}$, which takes into account the connective link 
between switches. The fourth switch is presumed failed, a probability of one. Therefore, probability of a failure of all four switches is conservatively estimated to be $6.72 \times 10^{-4}$.

Failure Event S652. There are another four bridge seismic clamps on the west side of the CSB. Only if all bridge seismic clamps are fully released is bridge travel allowed. The probability of a limit switch operating spuriously is assumed to be $8.76 \times 10^{-3}$ (EGG-SSRE-8875). To be conservative, the probability of failure is increased by a factor of 10 for the second switch and by a factor of 100 for the third switch to account for minor interactions or common cause links, if any. Therefore, the probability of failure is $8.76 \times 10^{-2}$ for the second switch and $8.76 \times 10^{-1}$ for the third switch. The probability of a failure of all three switches is estimated to be $\left(8.76 \times 10^{-3}\right) \times\left(8.76 \times 10^{-2}\right) \times\left(8.76 \times 10^{-1}\right)=6.72 \times 10^{-4}$, which takes into account the connective link between switches. The fourth switch is presumed failed, a probability of one. Therefore, probability of a failure of all four switches is conservatively estimated to be $6.72 \times 10^{-4}$

Failure Event S541. Only if all eight bridge seismic clamps are fully released is bridge travel allowed. Combining the probabilities of failure events $\mathrm{S} 65 \mathrm{I}$ and $\mathrm{S} 652$, the failure probability of the X-channel of interlock P4 is estimated to be $4.52 \times 10^{-7}$.

Failure Event $\mathbf{S 4 3 2}$. If the X-channel is defeated, interlock P4 is defeated. P4 has only one channel because it is classified as Hazard Class P. If interlock P4 is not credited for preventing an accident because it is Class $P$, the probability of this event is 1 . If interlock $\mathrm{P} 4$ is credited, the probability of failure of interlock P4 is $4.52 \times 10^{-7}$. In this study, it is conservatively assumed that the probability of failure of interlock P4 is one. No credit is taken for interlock P4.

\subsubsection{Defeat of Interlock P13}

Failure Events S661 and S662. Two proximity sensors are used to detect whether the trolley seismic locking pins are fully retracted. S661 and S662 are the failure events for the individual sensors. The probability of failure of a sensor is in the range of $1.0 \times 10^{-6}$ per hour (EGG-SSRE-8875, DP-1633). To simplify the calculation, the failure probability of the sensors is conservatively assumed to be $1.0 \times 10^{-2}$.

Failure Events S663and S664. Limit switches are used to detect whether the trolley locking jacks are fully retracted. There are two trolley locking jacks, with one limit switch per jack. Failure events S663 and S664 are the failure of an individual limit switch. The probability of a limit switch operating spuriously is conservatively assumed to be $8.76 \times 10^{-3}$

(EGG-SSRE-8875).

Failure Events S551 and S433. If all failure events from S661 through S664 occur, interlock P13 is defeated. Since interlock P13 is classified as Hazard Class P, credit may not be taken for preventing accidents. Therefore the probability is $1.0 \times 10^{\circ}$. If interlock P13 is credited, the probability of failure is $6.72 \times 10^{-4}$. In this study, it is conservatively assumed that the probability of failure of interlock P13 is one. No credit is taken for interlock P13. 
Failure Event S311. If interlocks P3, P4, and P13 are all defeated, the crane and trolley could move. If interlocks $\mathrm{P} 4$ and $\mathrm{P} 13$ are credited in preventing an accident, the probability of this event is $\left(5.89 \times 10^{-6}\right) \times\left(4.52 \times 10^{-7}\right) \times\left(6.72 \times 10^{-4}\right)=1.79 \times 10^{-15}$. If interlocks P4 and P13 are not credited, the probability of this event is $5.89 \times 10^{-6}$. To be conservative, no credit is taken for Hazard Class P single-channel interlocks in this analysis. Therefore, the probability of this event is $5.89 \times 10^{-6}$.

\subsubsection{Defeat of Interlock P21}

Failure Event $\mathbf{S 6 7 1}$. A limit switch detects whether the first bridge seismic clamp is fully applied. Failure of the limit switch closes a contactor in the X-channel of interlock P21. . The probability of the limit switch operating spuriously is conservatively assumed to be $8.76 \times 10^{-3}$ (EGG-SSRE-8875).

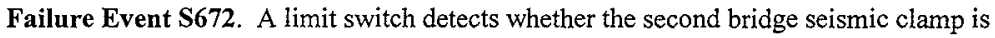
fully applied. Failure of the limit switch closes a contactor in the X-channel of interlock P21. The probability of the limit switch operating spuriously is conservatively assumed to be $8.76 \times 10^{-3}$ (EGG-SSRE-8875). If a factor of 10 increase is assumed in order to account for possible common mode effects, the probability of a limit switch failure is $8.76 \times 10^{-2}$.

Failure Event $\mathbf{S 6 7 3}$. A proximity sensor detects whether the first trolley restraint pin is applied. Failure of the sensor closes a contactor in the X-channel of interlock P21. The probability of failure of a sensor is in the range of $1.0 \times 10^{-6}$ per hour (EGG-SSRE-8875, DP-1633). A probability of $5.0 \times 10^{-6}$ per hour (an annual probability of $4.38 \times 10^{-2}$ ) is assumed.

Failure Event S674. A proximity sensor detects whether the second trolley restraint pin is applied. Failure of the sensor closes a contact in the X-channel of interlock P21. The probability of failure of a sensor is in the range of $1.0 \times 10^{-6}$ per hour (EGG-SSRE-8875, DP-1633). A probability of $5.0 \times 10^{-6}$ per hour (and annual probability of $4.38 \times 10^{-2}$ ) is assumed. The probability of a failure of a second sensor is increased by a factor of 10 to account for possible common mode effects, resulting in a value of $4.38 \times 10^{-1}$.

Failure Event S561. If failure events S671 through S674 all occur, the X-channel of interlock P21 is energized and considered defeated. The probability of all these events occurring is $\left(8.76 \times 10^{-3}\right) \times\left(8.76 \times 10^{-2}\right) \times\left(4.38 \times 10^{-2}\right) \times\left(4.38 \times 10^{-1}\right)=1.47 \times 10^{-5}$.

Failure Event S681. A limit switch detects whether the first bridge seismic clamp is fully applied. Failure of the limit switch closes a contactor in the Y-channel of interlock P21. The probability of the limit switch operating spuriously is conservatively assumed to be $8.76 \times 10^{-3}$ (EGG-SSRE-8875).

Failure Event S682. A limit switch detects whether the second bridge seismic clamp is fully applied. Failure of the limit switch closes a contactor in the Y-channel of interlock P21. The probability of the limit switch operating spuriously is conservatively assumed to be $8.76 \times 10^{-3}$ (EGG-SSRE-8875). The probability of a failure of a second limit switch is estimated to be $8.76 \times 10^{-2}$ to account for possible common mode effects. 
Failure Event $\mathbf{S 6 8 3}$. A proximity sensor detects whether the first trolley restraint pin is applied. Failure of the sensor closes a contactor in the Y-channel of interlock P21. The probability of failure of a sensor is in the range of $1.0 \times 10^{-6}$ per hour (EGG-SSRE-8875, DP-1633). A probability of $5.0 \times 10^{-6}$ per hour (an annual probability of $4.38 \times 10^{-2}$ ) is assumed.

Failure Event S684. A proximity sensor detects whether the second trolley restraint pin is applied. Failure of the sensor closes a contactor in the Y-channel of interlock P21. The probability of failure of a sensor is in the range of $1.0 \times 10^{-6}$ per hour (EGG-SSRE-8875, DP-1633). A probability of $5.0 \times 10^{-6}$ per hour (an annual probability of $4.38 \times 10^{-2}$ ) is assumed. The probability of a failure of a second sensor is estimated to be $4.38 \times 10^{-1}$ to account for possible common mode effects.

Failure Event S562. If failure events S681 through S684 all occur, the Y-channel of interlock P21 is energized and considered defeated. The probability of this event is $\left(8.76 \times 10^{-3}\right)$ $\times\left(8.76 \times 10^{-2}\right) \times\left(4.38 \times 10^{-2}\right) \times\left(4.38 \times 10^{-1}\right)=1.47 \times 10^{-5}$. An increase of a factor of ten is assumed in order to account for common mode effects between two independent channels, thus making the probability $1.47 \times 10^{-4}$.

Failure Event S441. If both the X-and Y-channels of interlock $\mathrm{P} 21$ are defeated, interlock P21 is defeated. Combining probabilities, the probability of a failure of interlock P21 is $\left(1.47 \times 10^{-5}\right) \times\left(1.47 \times 10^{-4}\right)=2.16 \times 10^{-9}$.

Failure Event S422. An earthquake occurs. The probability of a seismic event at the Hanford Site is in the range of $2.0 \times 10^{-4}$ (WHC-SD-W236A-TI-002).

Failure Event S312. If an earthquake occurs at the same time that interlock P21 is defeated, it is conservatively assumed that the turret will move to shear the MCO because the crane seismic clamps are not fully applied. Combining probabilities, the probability of this event is estimated to be $\left(2.16 \times 10^{-9}\right) \times\left(2.0 \times 10^{-4}\right)=4.32 \times 10^{-13}$.

Failure Event S201. The MCO shear can occur only if the MCO is between regions. The MCO hoist travels at a speed of around $5 \mathrm{ft} / \mathrm{min}$. For a $14-\mathrm{ft} \mathrm{MCO}$, the duration between regions should be no more than 5 minutes during normal MHM MCO hoist operation. Assuming that $200 \mathrm{MCOs}$ are handled at the CSB per year and that the average number of MHM lifts per MCO per year is 5, the total number of MHM lifts per year is 1,000 . The total duration MCOs are between regions in a year is estimated to be 87 hours. Therefore, the probability of an MCO being between regions is around $1.0 \times 10^{-2}$.

Failure Event S212. Crane and/or trolley movement or an earthquake can cause the turret to move laterally, but crane and/or trolley movement (failure event S311) dominates. The probability of the turret moving laterally is the same as for failure event S311 (i.e., $5.89 \times 10^{-6}$ ).

Failure Event S102. An MCO shear will occur if the MHM moves laterally when an MCO is between regions. This event is the combination of failure events S212 and S201. The probability is estimated to be $\left(1.0 \times 10^{-2}\right) \times\left(5.89 \times 10^{-6}\right)=5.89 \times 10^{-8}$. 


\subsubsection{Top Event}

The MCO shear occurs either because of turret rotation or because of MHM lateral movement. The probability is then the sum of failure events S101 and S102, or $\left(6.9 \times 10^{-8}\right)$ $+\left(5.89 \times 10^{-8}\right)=1.28 \times 10^{-7}$. The probability is conservatively estimated to be $1.28 \times 10^{-7}$.

Uncertainty was estimated on the solution of the fault tree. The estimate was based on 5,000 samples, mean values for failure probabilities, log normal distribution assumptions for the failure probability distribution, and an error factor of 10 for all failure probabilities except errors with a probability of one. The estimate show an uncertainty band between $2.7 \times 10^{-11}$ and $1.84 \times 10^{-7}$, based on $5 \%$ and $95 \%$ respectively.

\subsection{CONCLUSION}

This analysis shows that a shear of an MCO by the MHM is considered an incredible event during normal lifting operations. Based on this study, it is recommended that a good maintenance and testing program should be in place to ensure the interlocks (especially P6) are functioning properly. 


\subsection{FREQUENCY OF A MULTI-CANISTER OVERPACK DROP FROM THE MULTI-CANISTER OVERPACK HANDLING MACHINE}

\subsection{INTRODUCTION}

At the $\mathrm{CSB}, \mathrm{MCO}$ will be hoisted and transported using the $\mathrm{MCO}$ handling machine (MHM). The possibility of a dropping an MCO is inherent to such hoisting operations. Because the potential consequences of an unmitigated MCO drop from the MHM are unacceptable, the MHM was designed with multiple layers of protection to prevent such an event. This drop protection consists of both safety interlocks and mechanical design features. The safety interlocks sense the state of the MHM and its interaction with any $\mathrm{MCO}$ being handled. The interlocks then provide power availability for various $\mathrm{MCO}$ handling operations only when predetermined logic is met that demonstrates that such an operation will not result in the potential for the MCO to be dropped or otherwise damaged. MHM mechanical design features that reduce the likelihood of an MCO drop include a mechanical lock that holds the MHM MCO grapple jaws closed when a load is suspended and the single-failure-proof load path provided by the MHM MCO hoist.

The frequency analysis documented in SNF-4087, Evaluation to Determine the Frequency of a Multi-Canister Overpack Drop from the Multi-Canister Overpack Handling Machine at the Canister Storage Building, assesses the MHM design features that are intended to reduce the likelihood that an MCO could drop from the MHM MCO hoist. These features are considered individually and as a cohesive set to determine a conservative quantitative estimate of the annual frequency that is to be expected for drops of the MCO from the MHM. To obtain this annual drop frequency estimate, two primary failure modes were identified that should encompass all feasible fault paths that could lead to a drop. These failure modes are (1) the structural failure of MHM mechanical components relied upon to support a hoisted MCO and (2) the failure of the MHM safety interlocks to properly sense the state of the MHM and its interaction with an MCO.

\subsubsection{Probability of Structural Failure of Multi-Canister Overpack Handling Machine Mechanical Components}

The critical components of the MCO and MHM, including gantry crane, trolley, turret, hoist and grapple assemblies were evaluated for the factor of safety against failure, failure probability, and fatigue usage factor. The load cases considered were operational and design load plus design basis earthquake loads. Based on the evaluation performed for the load cases considered in this calculation, the following conclusions were made (SNF-4087).

- All critical components of the $\mathrm{MCO}$ for lifting have large safety factor against failure and fatigue is not a concern. Their failure probabilities are small $\left(<1.0 \times 10^{-15}\right)$.

- All critical components of the grapple assembly have large safety factor against failure and fatigue is not a concern. Their failure probabilities are small $\left(<1.0 \times 10^{-15}\right)$ 
- All critical components of the hoist assembly have large safety factor against failure and fatigue is not a concern. Their failure probabilities are small $\left(<1.0 \times 10^{-15}\right)$.

- All critical components of the turret have large factor against failure and fatigue is not a concern. Their failure probabilities are small $\left(<1.0 \times 10^{-15}\right)$.

- Most critical components of the gantry crane and trolley have large factor against failure and fatigue is not a concern. Their failure probabilities are small $\left(<1.0 \times 10^{-15}\right)$.

- Under the design load plus design basis earthquake, for the most critical trolley location and the MCO position, the critical components of the gantry crane and trolley have a minimum factor of 1.57 against failure and fatigue is not a concern. Their failure probabilities are small $\left(4.0 \times 10^{-9}\right)$.

- The failure probabilities of the trolley seismic locking pin, trolley $\mathrm{x}$-seismic restraints, turntable locking pin and turret base locking pin are small $\left(<1.0 \times 10^{-15}\right)$. Therefore, shearing of the $\mathrm{MCO}$ or MCO hoist cables by either rotation of the turret or lateral movement of the trolley during a seismic event is an incredible event.

Therefore, it was concluded that the critical components of the MHM have sufficient safety factor against failure. Assuming a constant MHM operation, the probability of an MCO drop due to the failure of the MHM components is small $\left(4.0 \times 10^{-9}\right)$. If the number of the MCO lifts is 1,000 times a year and the duration of each lift is assumed to be 1 hour, the maximum component failure probability for a design basis earthquake occurred during an $\mathrm{MCO}$ lift is $\left(4.0 \times 10^{-9}\right) \times(1,000 / 8,760)=5.0 \times 10^{-10}$.

\subsubsection{Probability of Failure of Multi-Canister Overpack Handling Machine Safety Interlocks}

The following conclusions were made based on the evaluation of the grapple-jaws-open and grapple-jaws-not-fully-closed interlock failures (SNF-4087).

- The failure probability of an MCO drop due to the grapple opening is very small $\left(3.62 \times 10^{-9}\right)$.

- The failure probability of and MCO drop due to grapple being not fully closed is very small $\left(1.25 \times 10^{-9}\right)$.

- Assumptions were made as to the impact of human errors, common cause events, and reliability.

The numbers above are annual probability of occurrence; however, the MHM will not be operating around the clock for the entire year. Actual operation will be approximately 800 to 
1,000 lifts/lowers per year at 20 minutes each, or conservatively at 1 hour each. The above numbers include all drops of $\mathrm{MCO}$ from the grapple even if the turret assembly is not rotated to the lift/lower position.

\subsection{CONCLUSION}

The MHM is designed against mechanical, structural, and interlock failures. The single-failure proof mechanical design combines with the strength of component materials and an aggressive maintenance and inspection program to ensure that a failure of the MHM that could lead to a drop of the MCO during a design basis seismic event will not occur. The multiple-layered and dual-channel electrical interlocks of the MHM work in conjunction with the periodic interlock testing, maintenance, and inspection, to ensure that the interlock system will not be defeated in a way that could lead to the drop of an MCO. The failure frequency analysis shows that the total expected $\mathrm{MCO}$ drop frequency from structural and interlock failures places these events in a range that is considered not credible (annual frequency of less than $10^{-6}$ ) (SNF-4087). 
SNF-4042 REV 0

This page intentionally left blank. 


\subsection{FREQUENCY OF OVERPRESSURIZATION OF \\ THE MULTI-CANISTER OVERPACK BY THE INERT GAS SYSTEM}

\subsection{INTRODUCTION}

Overpressurization of the $\mathrm{MCO}$ is a design basis accident scenario that is initiated by failure of the pressure regulator on the helium supply system while an $\mathrm{MCO}$ is in the sampling/weld station undergoing the helium backfill operation. The regulator, which reduces the gas cylinder pressure to approximately $120 \mathrm{lb} / \mathrm{in}^{2}$ gauge, must fail open, thereby resulting in the system piping downstream of the pressure regulator being pressurized to the helium storage cylinder pressure. The helium cylinder pressure could be well in excess of $2,000 \mathrm{lb} / \mathrm{in}^{2}$ gauge. This high pressure is assumed to consequentially fail pressure control valve PCV726. The purpose of PCV726 is to further reduce the helium pressure to approximately $0.5 \mathrm{~atm}$ for backfilling the $\mathrm{MCO}$ after sampling. During the backfilling operation, the $\mathrm{MCO}$ would then be exposed to the helium supply pressure (greater than $2,000 \mathrm{lb} / \mathrm{in}^{2}$ gauge), which exceeds the MCO design pressure. The design pressure of the helium piping associated with the MCO sampling operation is $150 \mathrm{lb} / \mathrm{in}^{2}$ gauge. It can be hypothesized that, following this scenario, some part of the sampling system pressure boundary fails resulting in blowdown of the $\mathrm{MCO}$ or that the $\mathrm{MCO}$ catastrophically fails and spews its contents into the CSB.

\subsection{PROBABILITY ESTIMATES}

A logic diagram, in fault tree format, was constructed (Figure 2) to assess the likelihood of $\mathrm{MCO}$ overpressurization that is initiated by failure of the pressure regulator on the helium supply system while the MCO is undergoing the helium backfill operation at the sampling/weld station. Each box with a circle underneath represents a failure that could contribute to a potential MCO overpressurization. The failures are combined through logic gates: AND gates (flat bottom, semicircle top) or OR gates (arched bottom and arrowhead top). An AND gate requires all inputs to the gate (from below) to occur for the result, described in the box above the gate, to occur. An OR gate only requires that any one input to the gate (from below) occur for the result, described in the box above the gate, to occur. Final estimates of the total likelihood of an MCO overpressurization resulting from failure of the pressure regulator on the helium supply system are obtained by properly combining the probabilities of each branch of the diagram according to Boolean algebra. The following text describes each event for each path of the logic fault tree. The descriptions include estimates used in the current analysis of the probability for each event to occur.

Failure Event R201. Pressure regulator valve PCV733, which reduces the gas cylinder pressure to approximately $120 \mathrm{lb} / \mathrm{in}^{2}$ gauge, fails open, thereby resulting in the system piping downstream of the pressure regulator being pressurized to the helium storage cylinder pressure. This helium cylinder pressure could be well in excess of $2,000 \mathrm{lb} / \mathrm{in}^{2}$ gauge. The probability of failure of the regulator valve is assumed to be $2.14 \times 10^{-6}$ per hour (Dexter and Perkins). The probability of failure in 8,760 hours ( 1 year) is $1.87 \times 10^{-2}$. 
Failure Event R101. It is conservatively assumed that the failure of pressure regulator valve PCV733 causes pressure control valve PCV726 to fail. Therefore, the failure probability of $\mathrm{PCV} 726$ is one.

Failure Event R102. Safety-class safety valve PSV728 fails. The pressure safety valves provide protection from pressure internal to the $\mathrm{MCO}$ and sampling system piping from exceeding design valuse when sampling the MCO. The probability that a safety valve fails to open is $3.0 \times 10^{-4}$ per demand (EGG-SSRE-8875).

Failure Event R103. Safety-class safety valve PSV720 fails. The probability that a safety valve fails to open is $3.0 \times 10^{-4}$ per demand (EGG-SSRE-8875). The probability is increased by a factor of ten to account for possible common mode effects between two safetyclass safety valves (i.e., $3.0 \times 10^{-3}$ ).

Failure Event R104. It is conservatively assumed that there is no breach of the sampling line following a failure of the regulator valve and both safety valves. The assumption is conservative since it means that the helium cylinder pressure will not be reduced because of a breach of the sampling line, but fully charged to rupture the $\mathrm{MCO}$. In reality, it is possible that the sampling line might be ruptured before the MCO pressure boundary challenged. The probability of this is event is assumed to be 1 .

Failure Event R105. It is conservatively assumed that the $\mathrm{MCO}$ is pressurized and eventually ruptured. Therefore, the probability for this event is assumed to be one.

Top Event. The probability of an MCO rupture as a result of overpressurization by the inert gas system during reinerting of a monitored MCO after sampling is $\left(1.87 \times 10^{-2}\right)$ $\times\left(3.0 \times 10^{-4}\right) \times\left(3.0 \times 10^{-3}\right)=1.68 \times 10^{-8}$. Assuming that $200 \mathrm{MCOs}$ per year will be sampled and that the sampling duration is 1 hour each, the annual frequency of overpressurization of an $\mathrm{MCO}$ by the inert gas system is $(200 / 8,760) \times\left(1.68 \times 10^{-8}\right)=3.84 \times 10^{-10}$.

Uncertainty was estimated on the solution of the fault tree. The estimate was based on 5,000 samples, mean values for failure probabilities, $\log$ normal distribution assumptions for the failure probability distribution, and an error factor of 10 for all failure probabilities except errors with a probability of one. The estimate show an uncertainty band between $1.55 \times 10^{-11}$ and $4.97 \times 10^{-8}$, based on $5 \%$ and $95 \%$ respectively.

\subsection{CONCLUSION}

The frequency of overpressurization of an $\mathrm{MCO}$ by the inert gas system is estimated to be in the order of $1.0 \times 10^{-10}$. Therefore, the event is not credible. 
SNF-4042 REV 0

\subsection{FREQUENCY OF A GASEOUS RELEASE RESULTING FROM A LEAK IN THE MULTI-CANISTER OVERPACK SAMPLING SYSTEM AT THE CANISTER STORAGE BUILDING}

\subsection{INTRODUCTION}

This section addresses the probability of an MCO gaseous release resulting from a leak in the MCO sampling system with a coincident loss of sample hood exhaust at the CSB. The MCO sampling system is used for withdrawing a sample of gases from the monitored MCOs using a predetermined schedule. At the MCO sampling station, gases in the MCO are sampled using the MCO sample cart.

A sample hood is positioned on top of the MCO for airborne radiological control. The sample hood is used to confine potential airborne contamination coming from an accidental MCO release during sampling operations. The sampling/weld station ventilation system, which is equipped with a high-efficiency particulate air (HEPA) filter exhauster, is relied upon for ventilating the hood. This is accomplished by connecting the sample hood flexible exhaust line to the sampling/weld station HEPA filtered exhaust fan. This exhaust fan provides a negative sample hood pressure relative to the sampling/weld area, maintains air contamination control around the sampling pit, and protects operating personnel from any MCO gases that might escape from the MCO to inside the hood during sampling operations.

Long-reach tools are used to remove and replace the MCO process port operator cover plate. MCO cover plate 2 is removed using hand tools, and the process valve operator is bolted to $\mathrm{MCO}$ port 2. All lines in the sample cart are purged with inert gas. An operator uses the $\mathrm{MCO}$ process valve operator to open the MCO process valve inside port 2 . Gases from inside the MCO flow through the MCO process valve filling the sampling line, HEPA filter, and flexible piping to the sample cart pressure gauge.

An MCO leak could occur following opening of the $\mathrm{MCO}$ process valve inside port 2. If at the same time, a loss of exhaust flow from the sample station hood occurred, the onsite dose consequence could exceed evaluation guidelines (Sellers 1997).

\subsection{PROBABILITY ESTIMATES}

A logic diagram, in fault tree format(Figure 3), was constructed to assess the likelihood of an MCO gaseous release from a leak in the sampling system with a coincident loss of sample hood exhaust. Each box with a circle underneath represents a failure that could contribute to a potential MCO shear. The failures are combined through logic gates: AND gates (flat bottom, semicircle top) or OR gates (arched bottom and arrowhead top). An AND gate requires all inputs to the gate (from below) to occur for the result, described in the box above the gate, to occur. An OR gate only requires that any one input to the gate (from below) occur for the result, described in the box above the gate, to occur. Final estimates of the total likelihood of an MCO gas release are obtained by properly combining the probabilities of each branch of the diagram. according to Boolean algebra. 
. The first assumption in the development of the fault tree is that the sample hood ventilation system works properly prior to opening the $M C O$ process valve. The second assumption is that the $\mathrm{MCO}$ process valve remains open for 1 hour during MCO sampling operation. This is based on the sequence of events identified in the operational sequence block flow diagram (H-2-123400). The time starts from connecting the sample equipment and ends at pressurizing the $\mathrm{MCO}$ with helium. A 30-minute time period is allocated for activities related to sample equipment connection, pressure check, and $\mathrm{MCO}$ gas sample extraction. An additional 10-minutes is allocated for venting the collected MCO gas. Finally, another 10 minutes is allocated for pressurizing the $\mathrm{MCO}$ with helium gas. The total is 50 minutes. To be conservative, 1 hour was assumed in this analysis.

The following text describes each event for each path of the logic fault tree. The descriptions include estimates used in the current analysis of the probability for each event to occur.

\subsubsection{Multi-Canister Overpack Leak}

Failure Event J501. The first basic event is a failure to tighten the spring bolts on the single valve operator assembly. The basic human error probability of $3.0 \times 10^{-2}$ (NUREG/CR-4772, Table 4-3, note 1) can be reduced to $3.010^{-3}$ because the operators are fully trained to perform the sampling operation, written procedures are in place, self-checking is performed, and operators will not perform their work in a stressful situation.

Failure Event J502. Cracks in the sample hood hose cause it to fail. The hose is made of steel with a design pressure of $150 \mathrm{lb} / \mathrm{in}^{2}$ gauge. The probability of a hose with cracks that might cause the hose to leak during sampling is considered to be remote. The probability of leakage for 1 to 3 in. pipes is $1.0 \times 10^{-8}$ per hour per foot (EGG-SSRE-8875). Conservatively, assuming $100 \mathrm{ft}$ of pipe and 100 hours of operation, the probability of pipe leakage is $1.0 \times 10^{-4}$.

Failure Event J401. Either failure event J501 or J502 causes a leak path to exist before the leak check is performed using a pressure test. The probability of this event is the same as that in event $\mathrm{J} 501$ (i.e., $3.0 \times 10^{-3}$ ).

Failure Event J402. A pressure test is performed, but no leak path is detected during the test. It is assumed that the test is performed based on highly reliable methods. The pressure test relies on a safety-significant pressure-indicating device to determine the sealed condition of the sample line. Moreover, the leak check is performed by persons independent from the persons responsible for the installation of the valve operator assembly. The probability for this failure event is assumed to be $1.0 \times 10^{-2}$ (NUREG/CR-4772, Table 4-3, Case VI).

Failure Event J301. Failure event J301 is a leak path that exists before the MCO is opened, which is the combination of events $\mathrm{J} 40 \mathrm{I}$ and $\mathrm{J} 402$. The probability of this event is in the range of $\left(3.0 \times 10^{-3}\right) \times\left(1.0 \times 10^{-2}\right)=3.0 \times 10^{-5}$. 
Failure Event 3201. It is assumed that once the MCO is opened, the MCO gas releases through an existing leak path (failure event $\mathrm{J301}$ ). The probability of this event is therefore the same as that for failure event $\mathrm{J} 301$ (i.e., $3.0 \times 10^{-5}$ ).

Failure Event $\mathbf{J 2 0 2}$. The $\mathrm{MCO}$ hose in the sample hood leaks because of a rupture during sampling. The design pressure of the hose is $150 \mathrm{lb} / \mathrm{in}^{2}$ gauge, and the hose is a safetysignificant component made of steel. The $\mathrm{MCO}$ gas pressure is well below the hose design pressure. Since the hose is not ruptured during pressure testing, it is unlikely that the MCO gas pressure will rupture the hose during sampling. Therefore, the probability of the hose leak due to rupture is considered to be remote. The rupture rate for 1 to $3 \mathrm{in}$. of pipe with water or steam working fluid is $5 \times 10^{-10}$ per hour per foot. For a 100 -ft pipe, the failure rate is $5.0 \times 10^{-9}$ per hour. A failure rate of $4.0 \times 10^{-6}$ is used in this study.

Failure Event J101. Either failure event J201 or failure event J202 causes the MCO leak. The probability of a leak occurring is around $3.5 \times 10^{-5}$.

\subsubsection{Loss of Filtered Ventilation in the Sampling Hood}

Failure Event J451. An average rate for loss of offsite power on the Hanford Site is 1.22/year (WHC-EP-0811). Therefore, the probability of a loss of offsite power during a 1-hour $\mathrm{MCO}$ process valve opening in a year is calculated to be $1.4 \times 10^{-4}$.

Failure Event J452. The motor fails during sampling. It is assumed that the ventilation system has one fan and one motor. The probability of the motor failing during sampling is estimated to be $3.0 \times 10^{-5}$ (EGG-SSRE-8875).

Failure Event J351. The motor stops running because of either failure event J451 or J452. The probability of this event is in the range of $1.7 \times 10^{-4}$.

Failure Event J601. The damper is closed before sampling. There are five dampers: MD-5, MD-6, MD-7, MD-8, and MD-9. Dampers MD-5, MD-6, and MD-7 are closed only for maintenance. The probability that these three dampers are closed during sampling is remote, and is considered negligible when compared with the probability of damper MD-8 being closed during sampling. Damper MD-9 would have no impact on the flow path from the sample hood to the exhaust system. If the ventilation system is taken out of service, no MCO sampling operation could be performed. A conservative probability of $3.0 \times 10^{-3}$ can be used for this event because the operators are fully trained to perform the operation, written procedures are in place, self-checking is performed, and operators will not perform their work in a stressful situation.

Failure Event J602. This event is a failure to detect that the damper is in a closed position even after a flow test has been performed. This is considered highly unlikely because the flow meter in the sample hood would have no flow indication during the flow test if the damper was closed. A conservative probability of $1.0 \times 10^{-2}$ is assumed (NUREG/CR-4772). 
Failure Event J552. Failure events J601 and J602 would both have to occur for the damper to be closed before the MCO sampling operation. Based on failure events J601 and $\mathrm{J} 602$, the probability for this event should be $\left(3.0 \times 10^{-3}\right) \times\left(1.0 \times 10^{-2}\right)=3.0 \times 10^{-5}$.

Failure Event J551. The operator could inadvertently close the damper during sampling when the $\mathrm{MCO}$ process valve is in the open position. This is considered highly unlikely because the operator will have no reason, and will have no chance, to physically close the damper during sampling operation. Furthermore, the damper has no automatic control; once the damper is opened, the damper is in a locked open position. Therfore, a probability of $1.0 \times 10^{-4}$ can be assumed for this event.

Failure Event $\mathbf{J 4 5 5}$. This failure event addresses the overall chance that the damper is closed during sampling operation when the $\mathrm{MCO}$ process valve is open. Either failure event J551 or failure event J552 would have to occur, therefore the probability of this failure event is $\left(1.0 \times 10^{-4}\right)+\left(3.0 \times 10^{-5}\right)=1.3 \times 10^{-4}$.

Failure Event J456. The duct is ruptured during sampling. This could be caused by a seismic event. The probability of a seismic event at the Hanford Site is in the range of $2.0 \times 10^{-4}$ per year. The probability of the duct rupture during sampling is therefore in the range of $2.0 \times 10^{-8}$. A probability of $2.0 \times 10^{-6}$ was used in this analysis.

Failure Event J352. The flow path in the ventilation system is blocked during sampling. It is assumed that this failure event is caused either by failure event $\mathrm{J} 455$ or by failure event J456. Therefore, the probability should be in the range of $\left(1.3 \times 10^{-4}\right)+\left(2.0 \times 10^{-6}\right)=1.3 \times 10^{-4}$.

Failure Event J251. The heating, ventilation, and air conditioning (HVAC) system loses ventilation flow during sampling because either the motor stops or the flow path is blocked in the ventilation system. Summing the probabilities of failure event $\mathrm{J} 351$ and event $\mathrm{J} 352$ yields the probability of failure for event $\mathrm{J} 251$, which is $\left(1.7 \times 10^{-4}\right)+\left(1.3 \times 10^{-4}\right)=3.0 \times 10^{-4}$.

Failure Event J252. The HEPA filter does not function as designed because of manufacturing defects or maintenance errors. The probability should be very low because the HEPA filter is designated as a safety-significant item, and quality procedures are followed for HEPA filter acceptance and maintenance. The probability and the consequence of failure of this event should be less than that of failure event $\mathbf{J} 251$. It is assumed that event $\mathbf{J} 251$ dominates. A small probability of $1.0 \times 10^{-5}$ is judged to be appropriate for failure event J252.

Failure Event J453. The exhaust line to the sample hood has not been connected or has not been connected correctiy. The hose is not be routinely disconnected once it was installed. In addition, the operators are fully trained to perform the sampling, operation, written procedures are in place, self-checking is performed, and operators will not perform their work in a stressful situation. The basic human error probability can be reduced from of $3.0 \times 10^{-2}$ (NUREG/CR-4772) to $3.0 \times 10^{-3}$ for this event.

Failure Event J454. The exhaust line has cracks. The probability should be very low. The probability of leakage for 1 to 3 in. pipes is $1.0 \times 10^{-8}$ per hour per foot (EGG-SSRE-8875). 
Conservatively assuming $100 \mathrm{ft}$ of pipe and 100 hours of operation, the probability of pipe leakage is $1.0 \times 10^{-4}$.

Failure Event J353. Either failure event $J 453$ or failure event $J 454$ can cause a leak path in the exhaust line to exist prior to the start of sampling operation. The probability should be $\left(3.0 \times 10^{-3}\right) \times\left(1.0 \times 10^{-4}\right)=3.0 \times 10^{-3}$.

Failure Event $\mathbf{J 3 5 4}$. This is a failure to detect the leak path in the exhaust line during a flow test. The flow meter is in the sample hood area that is upstream of the fan and the exhaust line connection, so the flow test will detect that the exhaust line is not connected or that it leaks. A small leak path in the exhaust line would have no consequence because the pressure difference across the exhaust line allows only inleakage. The probability is assumed to be $1.0 \times 10^{-2}$ (NUREG/CR-4772).

Failure Event $\mathbf{J} 253$. If both failure event $\mathrm{J} 353$ and failure event $\mathrm{J} 354$ occur, the exhaust line can leak prior to the start of sampling. The combined probability is $\left(3.0 \times 10^{-3}\right)$ $\times\left(1.0 \times 10^{-2}\right)=3.0 \times 10^{-5}$.

Failure Event J102. HEPA ventilation operation is lost during sampling. Failure event J251 dominates this event. Therefore, a probability of $3.43 \times 10^{-4}$ is calculated for this event.

\subsubsection{Top Event}

The top event is the combination of failure event $\mathrm{J} 101$ and failure event $\mathrm{J} 102$. Failure events J101 and J102 together cause an MCO leak coincident with a loss of HEPA-filtered ventilation during sampling. The probability of this top event is $\left(3.5 \times 10^{-5}\right) \times\left(3.43 \times 10^{-4}\right)$ $=1.20 \times 10^{-8}$.

Uncertainty was estimated on the solution of the fault tree. The estimate was based on 5,000 samples, mean values for failure probabilities, log normal distribution assumptions for the failure probability distribution, and an error factor of 10 for all failure probabilities except errors with a probability of one. The estimate show an uncertainty band between $1.68 \times 10^{-10}$ and $3.54 \times 10^{-8}$, based on $5 \%$ and $95 \%$ respectively.

\subsection{CONCLUSIONS}

The total number of MCOs sampled has a direct impact on the frequency of the top event. If $24 \mathrm{MCO}$ samples are performed every year, the frequency would be in the range of $2.88 \times 10^{-7}$, which is considered incredible.

In conclusion, the potential for an MCO leak from around the valve operator and the hose in the sample hood with a coincident loss of exhaust flow from the sample station hood during MCO sampling at the CSB is considered to be incredible. 
The following measures and controls should be implemented prior to and during the MCO sampling operation to ensure that the assumptions used in this frequency estimate are met.

- It was assumed that adequate airflow exists through the sample hood and the HEPA filter prior to initiation of MCO sampling operations. The airflow should be verified based on highly reliable methods in accordance with written verification procedures.

- Operations involved with line connections (including the exhaust line) that might have potential for releasing MCO gases should be performed in accordance with written verification procedures.

- A leak check based on highly reliable methods should be performed prior to opening of the MCO process valve. The leak check should be performed by persons independent of those responsible for the installation of the process valve operator and the sample lines to the sample hood connection. The leak check should be performed in accordance with written verification procedures.

- Operators should be well trained for line connections that might have potential for releasing $\mathrm{MCO}$ gases. 


\subsection{FREQUENCY OF MULTI-CANISTER OVERPACK INTERNAL EXPLOSION AT THE CANISTER STORAGE BUILDING}

\subsection{INTRODUCTION}

Cover cap welding on selected MCOs will be delayed for about 1 year to allow for gas sampling at the CSB. An MCO to be sampled is moved to the sampling/weld station pit and a sample hood is placed over the MCO. Connections are made to the MCO sample port and MCO gas is collected using the positive pressure of the MCO. If the pressure in the MCO drops below $4 \mathrm{lb} / \mathrm{in}^{2}$ gauge, inert gas is added to raise the pressure. Flammable mixtures of hydrogen and oxygen could be formed in the MCO if the inert gas is contaminated with oxygen.

\subsection{PROBABILITY ESTIMATES}

A logic diagram, in fault tree format, was constructed (Figure 4) to assess the likelihood of an MCO internal explosion. Each box with a circle underneath represents a failure that could contribute to a potential MCO shear. The failures are combined through logic gates: AND gates (flat bottom, semicircle top) or OR gates (arched bottom and arrowhead top). An AND gate requires all inputs to the gate (from below) to occur for the result, described in the box above the gate, to occur. An OR gate only requires that any one input to the gate (from below) occur for the result, described in the box above the gate, to occur. Final estimates of the total likelihood of an MCO internal explosion are obtained by properly combining the probabilities of each branch of the diagram according to Boolean algebra. The following text describes each event for each path of the logic fault tree. The descriptions include estimates used in the current analysis of the probability for each event to occur.

Failure Event I401. Helium contaminated with oxygen is not detected. Oxygen bottles are mistakenly used as helium bottles, or helium bottles are contaminated with oxygen. The chances for such mistakes are rare because the oxygen bottle and the helium bottle are unlike. The bottles are different colors, and they are labeled as to the type of gas contained. The supplier should have a quality assurance program to ensure a high quality standard for helium bottles. It is conservative to assumed that the probability that the supplier delivered a wrong bottle is $1.0 \times 10^{-3}$. A sitewide procedure at CSB that requires inspection and/or verification of the bottle contents is in place to control the receipt of helium bottles. A TSR is in place to ensure that the helium received at CSB for use in the inert gas system is tested for purity. The probability that oxygen bottles are mistakenly used as helium bottles or that belium bottles are contaminated with oxygen should be reduced by a factor of ten, which is $1.0 \times 10^{-4}$.

Failure Event I402. The helium contaminated with oxygen has a concentration higher than $19 \%$. It is assumed that the lower the contaminated oxygen concentration, the higher the probability. So, there is an $80 \%$ chance that the oxygen concentration will be higher than $19 \%$. The probability of failure of this event is 0.8 .

Failure Event I301. If failure events 1401 and I 402 are both true, the MCO is contaminated with oxygen at a concentration higher than $19 \%$. This could happen if either 
helium bottles are accidentally filled with oxygen or oxygen bottles are accidentally used in place of helium bottles. Such mistakes are rare because the oxygen bottle and the helium bottle are unlike. The bottles are different colors, and they are labeled as to the type of gas contained. The supplier should have a quality assurance program to ensure a high quality standard for helium bottles. A sitewide procedure requiring inspection and /or verification of the bottle contents should be in place to control the receipt of helium bottles. The probability of failure is $\left(1.0 \times 10^{-4}\right) \times(0.8)=8.0 \times 10^{-5}$ for this event.

Failure Event 1501. Good sampling practice is not followed. As little sample gas as possible should be taken from the MCO during sampling. Using a sampling operation that minimizes the need to refill the MCO with inert gas reduces the frequency with which this accident could occur. Good engineering practices during the sampling process are likely to be followed because the good sampling operation is considered defense in depth for prevention of flammable gas mixtures within the MCO at the sampling station. A human error probability of $1.0 \times 10^{-2}$ is assumed (NUREG/CR-4772).

Failure Event 1403. If good sampling practice is not followed, there is a chance that the $\mathrm{MCO}$ will be depressurized. It is judged that there is a fifty-fifty chance that the MCO will be depressurized. The probability that the MCO will be depressurized is assumed to be 0.5 in this study.

Failure Event 1302. In failure event 1302, the operator recharges a depressurized MCO with helium. If the MCO still has adequate pressure for sampling operations after an inadvertent depressurization of the $\mathrm{MCO}$, the operator will not recharge a depressurized $\mathrm{MCO}$ with helium. Because of a lack of data, it is assumed that there is a fifty-fifty chance that the operator will recharge a depressurized $\mathrm{MCO}$ with helium. The probability is again assumed to be 0.5 . Combining this with the probabilities of failure events 1501 and I403, the probability of the operator recharging a depressurized MCO is $\left(1.0 \times 10^{-2}\right) \times(0.5) \times(0.5)=2.5 \times 10^{-3}$.

Failure Event 1201. If failure events $\mathrm{I} 301$ and $\mathrm{I} 302$ are both true, the $\mathrm{MCO}$ is recharged with helium that is contaminated with oxygen. The probability is the combined probability of failure events $\mathrm{I} 301$ and I302, a value of $\left(8.0 \times 10^{-5}\right) \times\left(2.5 \times 10^{-3}\right)=2.0 \times 10^{-7}$.

Failure Event I411. In failure event I41 1, air is in the supply lines because they have not been fully purged. The basic human error of omission probability of $2.0 \times 10^{-2}$ is assumed for this event (NUREG/CR-4772).

Failure Event 1412. In this event, the supply lines are not verified as fully inert. A basic human error probability of $3.0 \times 10^{-2}$ is assumed for a failure of verification that the supply lines are fully inert (NUREG/CR-4772).

Failure Event I303. If failure events $I 411$ and $I 412$ are both true, air may exist in the supply lines. Combining the probabilities of failure events 1411 and I412, the probability of air existing in the supply lines is $\left(2.0 \times 10^{-2}\right) \times\left(3.0 \times 10^{-2}\right)=6.0 \times 10^{-4}$. 
Failure Event 1202 . If failure events 1302 and 1303 are both true, the $\mathrm{MCO}$ is recharged using supply lines that are contaminated with air. The probability is the combined probability of failure events 1302 and 1303 , a value of $\left(2.5 \times 10^{-3}\right) \times\left(6.0 \times 10^{-4}\right)=1.5 \times 10^{-6}$.

Failure Event 1102. If either failure event $\mathrm{I} 201$ or failure event 1202 is true, air is assumed to exist inside the MCO. The probability that air exists inside the MCO is $\left(2.0 \times 10^{-7}\right)$ $+\left(1.5 \times 10^{-6}\right)=1.7 \times 10^{-6}$.

Failure Event I103. Adequate water is required inside the $\mathrm{MCO}$ for sufficient hydrogen to be generated to form a flammable mixture with oxygen. The MCO is processed at the Cold Vacuum Drying Facility, but the tempered water heater temperature sensing instrumentation could be miscalibrated, indicating that the $\mathrm{MCO}$ had passed all tests before it was received at the CSB. The probability that the sensing instrumentation is miscalibrated is based on basic human error probability $\left(3.0 \times 10^{-2}\right)$ and post-maintenance/post-calibration test failure probability. The post-calibration test is judged to represent the test performed following calibration that functionally tests that the temperature-sensing instrumentation reads the correct temperature of the tempered water. The post-maintenance/post-calibration test failure probability value is $1.0 \times 10^{-2}$ (NUREG/CR-4772). The probability that both failures will occur is $\left(3.0 \times 10^{-2}\right)$ $\times\left(1.0 \times 10^{-2}\right)=3.0 \times 10^{-4}$. Therefore, the probability that a flammable mixture exists inside the MCO is $\left(1.7 \times 10^{-6}\right) \times\left(3 \times 10^{-4}\right)=5.1 \times 10^{-10}$.

Failure Event I101. It is conservatively assumed that an ignition source is always present. The probability of this is event is therefore one.

Top Event. If both failure events 1103 and 1101 are true, the $\mathrm{MCO}$ may experiece an internal explosion. Combining the probabilities of 1103 and I101, the probability of an MCO internal explosion is $5.1 \times 10^{-10}$. Twenty-four MCOs per year are to be sampled at the CSB. The frequency of an MCO internal explosion at the CSB is $(24) \times\left(5.1 \times 10^{-10}\right)=1.22 \times 10^{-8}$.

Uncertainty was estimated on the solution of the fault tree. The estimate was based on 5,000 samples, mean values for failure probabilities, $\log$ normal distribution assumptions for the failure probability distribution, and an error factor of 10 for all failure probabilities except errors with a probability of one. The estimate show an uncertainty band between $1.0 \times 10^{-14}$ and $5.53 \times 10^{-10}$, based on $5 \%$ and $95 \%$ respectively.

\subsection{CONCLUSION}

The MCO internal explosion accident at the CSB is an incredible event. This is because there is a TSR in place to ensure that the helium received at CSB for use in the inert gas system is tested for purity. 
SNF-4042 REV 0

This page intentionally left blank.

snf-4042.doc 


\subsection{FREQUENCY OF MULTI-CANISTER OVERPACK EXTERNAL EXPLOSION AT THE CANISTER STORAGE BUILDING}

\subsection{INTRODUCTION}

Cover cap welding on selected MCOs will be delayed for about 1 year to allow for gas sampling at the CSB. Connections are made to the MCO sample port, and MCO gas is collected using the positive pressure of the MCO. If the connection to the MCO fails and discharges $M C O$ gas into the sample hood, an explosive mixture of hydrogen and air could be formed in the hood.

\subsection{PROBABILITY ESTIMATES}

A logic diagram, in fault tree format, was constructed (Figure 5) to assess the likelihood of an MCO external explosion. Each box with a circle underneath represents a failure that could contribute to a potential MCO shear. The failures are combined through logic gates: AND gates (flat bottom, semicircle top) or OR gates (arched bottom and arrowhead top). An AND gate requires all inputs to the gate (from below) to occur for the result, described in the box above the gate, to occur. An OR gate only requires that any one input to the gate (from below) occur for the result, described in the box above the gate, to occur. Final estimates of the total likelihood of an MCO external explosion are obtained by properly combining the probabilities of each branch of the diagram according to Boolean algebra. The following text describes each event for each path of the logic fault tree. The descriptions include estimates used in the current analysis of the probability for each event to occur.

Failure Event E201. The sample line is not connected correctly because of operator error. The probability of failure to connect correctly is assumed to be $3.0 \times 10^{-2}$ (NUREG/CR-4772).

Failure Event E202. The sample line connections, operator, and hose assembly are not pressure tested. The probability of failure to verify the sample line connection by performing the pressure test is $3.0 \times 10^{-2}$ (NUREG/CR-4772).

Failure Event E202. Independent verification of the sample line connections is not conducted. The probability of failure to independently verify that the sample line is connected correctly and the pressure test was passed is $3.0 \times 10^{-2}$ (NUREG/CR-4772).

Failure Event E101. The sample line fails. Hydrogen leaks out because of a crack in the sample line or because of failure to connect the line correctly. This event requires that failure events E201, E202, and E203 all be true. Combining the probabilities of failure events E210, E202, and E203, the probability of sample line failure is $\left(3.0 \times 10^{-2}\right) \times\left(3.0 \times 10^{-2}\right) \times\left(3.0 \times 10^{-2}\right)$ $=2.7 \times 10^{-5}$.

Failure Event E102. It is conservatively assumed that an ignition source is always present. The probability of this is event is therefore 1 . 
Failure Event E103. This event is the failure of sampling hood flow. The probability of failure event J102 in Section 5.0 of this report is $3.43 \times 10^{-4}$. However, to be conservative, a probability of $8.8 \times 10^{-4}$ is assumed for failure event E103.

Top Event. If failure events E101, E102, and E103, are all true, an MCO external explosion could occur. The probability of an MCO external explosion is the combined probabilities of failure events $\mathrm{E} 101, \mathrm{E} 102$, and $\mathrm{E} 103$, which is $\left(2.7 \times 10^{-5}\right) \times(1.0) \times\left(8.8 \times 10^{-4}\right)$ $=2.38 \times 10^{-8}$. Twenty-four MCOs per year will be sampled. The frequency of an MCO external explosion is conservatively estimated to be $(24) \times\left(2.38 \times 10^{-8}\right)=5.71 \times 10^{-7}$ per year. Therefore, an MCO external explosion is considered to be an incredible event.

Uncertainty was estimated on the solution of the fault tree. The estimate was based on 5,000 samples, mean values for failure probabilities, log normal distribution assumptions for the failure probability distribution, and an error factor of 10 for all failure probabilities except errors with a probability of one. The estimate show an uncertainty band between $4.6 \times 10^{-12}$ and $4.68 \times 10^{-8}$, based on $5 \%$ and $95 \%$ respectively.

\subsection{CONCLUSIONS}

This analysis shows that the MCO external explosion accident is an incredible event. However, the following measures and controls should be implemented before and during the MCO sampling operation to ensure that the assumptions used to estimate this event frequency are met.

- Operations involved with line connections (including exhaust line) that might have potential for releasing MCO gases should be performed in accordance with written verification procedures.

- A leak check based on highly reliable methods should be performed prior to opening the MCO process valve. The leak check should be performed by independent persons rather than the persons who are responsible for the installation of the process valve operator and the sample lines to the sample hood connection. The leak check should be performed in accordance with written verification procedures.

- Operators should be well trained for performing the line connections that might have potential for releasing $\mathrm{MCO}$ gases. 


\subsection{FREQUENCY OF THERMAL RUNAWAY ACCIDENT \\ IN A MULTI-CANISTER OVERPACK AT THE \\ CANISTER STORAGE BUILDING}

\subsection{INTRODUCTION}

A thermal runaway reaction could occur in an $\mathrm{MCO}$ at the CSB (1) if fuel temperatures were extremely high and (2) if there were enough water or oxygen. The pressure inside the $\mathrm{MCO}$ would increase because of increasing temperature and the production of gas and vapor. If pressure inside the $\mathrm{MCO}$ continued to increase to the point that the $\mathrm{MCO}$ pressure boundary was challenged, the $\mathrm{MCO}$ could fail and release radioactive particulate and hydrogen gas into the surrounding environment.

Calculations show that the $\mathrm{MCO}$ design pressure is high enough to provide a large margin of safety with regard to gas production from uranium-water and hydride-water chemical reactions (HNF-3553, Annex A). The calculation demonstrates that a runaway event caused by uranium-water and hydride-water reactions is not credible at the CSB if the MCOs satisfy the dryness tests at the Cold Vacuum Drying Facility and if the aluminum hydroxide thermal decomposition data remain valid.

Another way to generate heat in an $\mathrm{MCO}$ is for oxygen (or air) to enter as the result of some event. For this case, calculations show that the MCO gas pressure stays far below the MCO design pressure of $450 \mathrm{lb} / \mathrm{in}^{2}$ gauge (HNF-3553, Annex A).

This analysis investigates the frequency of a radioactive release from the MCO caused either by excess water or by an oxygen or air reaction with the fuel in an MCO at the CSB.

\subsection{PROBABILITY ESTIMATES}

A logic diagram, in fault tree format, was constructed (Figure 6) to assess the likelihood of a thermal runaway reaction in an $\mathrm{MCO}$. Each box with a circle underneath represents a failure that could contribute to a potential MCO shear. The failures are combined through logic gates: AND gates (flat bottom, semicircle top) or OR gates (arched bottom and arrowhead top). An AND gate requires all inputs to the gate (from below) to occur for the result, described in the box above the gate, to occur. An OR gate only requires that any one input to the gate (from below) occur for the result, described in the box above the gate, to occur. Final estimates of the total likelihood of a thermal runaway reaction in an $\mathrm{MCO}$ are obtained by properly combining the probabilities of each branch of the diagram according to Boolean algebra. The following text describes each event for each path of the logic fault tree. The descriptions include estimates used in the current analysis of the probability for each event to occur. 


\subsubsection{Thermal Runaway Caused by Reaction with Air}

Failure Event T401. A loss of cooling occurs at the sampling/weld station. An HVAC unit chilled by glycol cools two sampling/weld stations. The failure rate (fail to run) for air conditioning units is $3.0 \times 10^{-5}$ per hour (EGG-SSRE-8875). It is conservatively assumed that the probability of failure is $1.0 \times 10^{-4}$ per hour $\left(8.8 \times 10^{-1}\right.$ in 8,760 hours $)$.

Failure Event T402. The MCO temperature starts to increase once the cooling is lost at the sampling/welding station. Calculations show that the MCO wall temperature will reach $132^{\circ} \mathrm{C}$ after at least 50 days without cooling (HNF-3553, Annex A). The combined probability of the failure to recover cooling within 50 days and the failure to remove the MCO from the sampling/weld station within 50 days is very remote. The MCO normally will not stay at the station for more than 1 day, and the operation of the HVAC unit could be resumed at most in a matter of days. A very small probability of $1.0 \times 10^{-7}$ is assumed for this event. (This is based on the assumption that the probability of failure of the MHM is $1.0 \times 10^{-3}$, and the probability of failure of a cooling recovery after 50 days is $1.0 \times 10^{-4}$.)

Failure Event T301. If the fuel temperatures are extremely high and there is enough water or oxygen, the chemical reaction rates increase and produce more gases and heat. The probability of a high fuel temperature is the combined probabilities of failure events $\mathrm{T} 401$ and $\mathrm{T} 402$, which is $\left(8.8 \times 10^{-1}\right) \times\left(1.0 \times 10^{-7}\right)=8.8 \times 10^{-8}$.

Failure Event T302. The MCO is injected with oxygen at the sampling/weld station instead of helium. Oxygen bottles are mistakenly used as helium bottles, or helium bottles are contaminated with oxygen. The chances for such kind of mistakes are rare because the oxygen bottle and the helium bottle are unlike. The bottles are different colors, and they are labeled as to the type of gas contained. The supplier should have a quality assurance program to ensure a high quality standard for helium bottles. It is conservatively to assumed that the probability that the supplier delivered a wrong bottle is $1.0 \times 10^{-3}$. Since a sitewide procedure at CSB that requires inspection and/or verification of the bottle contents should be in place to control the receipt of helium bottles, the probability that oxygen bottles are mistakenly used as helium bottles, or helium bottles are contaminated with oxygen should be reduced by a factor of ten, which yields a probability of $1.0 \times 10^{-4}$.

Failure Event T201. If the fuel temperature in the MCO is high enough and there is enough oxygen, the probability of thermal runaway reaction increases. If failure events T301 and $\mathrm{T} 302$ are both true, the thermal runaway is initiated. The probability that the thermal runaway occurs is the combined probabilities of failure events $\mathrm{T} 301$ and $\mathrm{T} 302$, which is $\left(8.8 \times 10^{-8}\right) \times\left(1.0 \times 10^{-4}\right)=8.8 \times 10^{-12}$.

Failure Event T101. It is conservatively assumed that once the thermal runaway starts, the MCO pressure boundary is challenged. Therefore, the probability is the same as for failure event T201, which is $8.8 \times 10^{-12}$ that the pressure boundary will be challenged.

Failure Event T401. A loss of cooling occurs at the sampling/weld station. An HVAC unit chilled by glycol cools two sampling/weld stations. The failure rate (fail to run) for air 
conditioning units is $3.0 \times 10^{-5}$ per hour (EGG-SSRE-8875). It is conservatively assumed that the probability of failure is $1.0 \times 10^{-4}$ per hour $\left(8.8 \times 10^{-1}\right.$ in 8,760 hours $)$.

Failure Event T402. The MCO temperature starts to increase once the cooling is lost at the sampling/welding station. Calculations show that the MCO wall temperature will reach $132^{\circ} \mathrm{C}$ after at least 50 days without cooling. The combined probability of the failure to recover cooling within 50 days and the failure to remove the $\mathrm{MCO}$ from the sampling/weld station within 50 days is very remote. The MCO normally will not stay at the station for more than 1 day, and the operation of the HVAC unit could be resumed at most in a matter of days. A very small probability of $1.0 \times 10^{-7}$ is assumed for this event. (This is based on the assumption that the probability of failure of the MHM is $1.0 \times 10^{-3}$, and the probability of failure of a cooling recovery after 50 days is $1.0 \times 10^{-4}$.)

Failure Event T311. If the fuel temperature are extremely high and there is enough water or oxygen, the chemical reaction rates increase and produce more gases and heat. The probability of high fuel temperatures is the combined probabilities of failure events T401 and T400, which is $8.8 \times 10^{-8}$.

Failure Event T312. It is assumed that the MCO is completely sheared, which ensures plenty of oxygen for a potential thermal runaway reaction. The probability of a complete shear, $1.28 \times 10^{-7}$, is taken from the analysis of the frequency of a shear of an MCO by the MHM at the CSB. (Section 2.0 of this report).

Failure Event T202. If failure events T311 and T312 are both true, the thermal runaway reaction inside the $\mathrm{MCO}$ will start. Combining the probabilities for failure events $\mathrm{T} 311$ and T312 yields $\left(8.8 \times 10^{-8}\right) \times\left(1.28 \times 10^{-7}\right)=1.13 \times 10^{-14}$.

Failure Event T102. In failure event T102, the MCO pressure boundary is challenged by the thermal runaway reaction. Since the MCO has been completely sheared, the pressure boundary has already been challenged. The probability of failure event $\mathrm{T} 102$ is the same as that for failure event T202 (i.e., $1.13 \times 10^{-14}$ ).

\subsubsection{Thermal Runaway Caused by Reaction with Water}

Failure Event T321. Adequate water is required inside the MCO for a thermal runaway reaction to occur. The projected bounding inventory of free water in an MCO received at the CSB is $200 \mathrm{~g}$. Calculations have demonstrated that a thermal runaway accident at the CSB is not credible if the MCO contains less than $200 \mathrm{~g}$ of free water (HNF-3553, Annex A). In failure event T321, the MCO is assumed to contain more than $200 \mathrm{~g}$ of free water. The MCO is processed at the Cold Vacuum Drying Facility, but the tempered water heater temperature sensing instrumentation could be miscalibrated, indicating that the $\mathrm{MCO}$ had passed all tests before it was received at the CSB. The probability that the sensing instrumentation is miscalibrated is based on basic human error probability $\left(3.0 \times 10^{-2}\right)$ and post-maintenance/postcalibration test failure probability. The post-calibration test is judged to represent the test performed following calibration that functionally tests that the temperature-sensing instrumentation reads the correct temperature of the tempered water. The post- 
maintenance/post-calibration test failure probability value is $1.0 \times 10^{-2}$ (NUREG/CR-4772). The probability that both failures will occur is $\left(3.0 \times 10^{-2}\right) \times\left(1.0 \times 10^{-2}\right)=3.0 \times 10^{-4}$. Therefore, the probability that a flammable mixture exists inside the MCO is $\left(1.7 \times 10^{-6}\right) \times\left(3 \times 10^{-4}\right)$ $=5.1 \times 10^{-10}$.

Failure Event T322. In this event, heat removal is less than heat generation in the MCO. If a loss of cooling were to occur at the sampling/weld station, the heat removal rate might be less than the heat generation in the MCO. The two sampling/weld stations are chilled by one HVAC unit using glycol coolant. The failure rate (fail to run) for air conditioning units is $3.0 \times 10^{-5}$ per hour (EGG-SSRE-8875). It is conservatively assumed that the probability of failure is $1.0 \times 10^{-4}$ per hour $\left(8.8 \times 10^{-1}\right.$ in 8,760 hours $)$. . The MCO temperature starts to increase once the cooling is lost at the sampling/welding station. Calculations show that the $\mathrm{MCO}$ wall temperature will reach $132^{\circ} \mathrm{C}$ after at least 50 days without cooling (HNF-3553, Annex A). The combined probability of the failure to recover cooling within 50 days and the failure to remove the $\mathrm{MCO}$ from the sampling/weld station within 50 days is very remote. The MCO normaily will not stay at the station for more than 1 day, and the operation of the HVAC unit could be resumed at most in a matter of days. A very small probability of $1.0 \times 10^{-7}$ is assumed for this event. This is based on the assumption that the probability of failure of the MHM is $1.0 \times 10^{-3}$, and the probability of failure of a cooling recovery after 50 days is $1.0 \times 10^{-4}$. If the fuel temperatures are extremely high and there is enough water or oxygen, the chemical reaction rates increase and produce more gases and heat. The probability of a high fuel temperature is the combined probabilities of air conditioning failure and cooling recovery failure, which is $\left(8.8 \times 10^{-1}\right) \times\left(1.0 \times 10^{-7}\right)=8.8 \times 10^{-8}$.

Failure Event T203. If failure events T321 and T322 are both true, a thermal runaway reaction could occur in an MCO. The probability is the combined probabilities of failure events $\mathrm{T} 321$ and $\mathrm{T} 322$, which is $\left(3.0 \times 10^{-4}\right) \times\left(8.8 \times 10^{-8}\right)=2.64 \times 10^{-11}$.

Failure Event T103. Failure event T103 is the same as failure event T203. Therefore, the probability is $2.64 \times 10^{-11}$.

\subsubsection{Top Event}

Once the MCO pressure boundary has been challenged, it is assumed that radioactive particulate will be released to the environment. The probability of the top event is the probability of failure event $T 101$ plus the probability of failure event $T 102$ plus the probability of failure event $\mathrm{T} 103$ (i.e., $3.52 \times 10^{-11}$ ). Twenty-four MCOs per year will be sampled, so the frequency of a thermal runaway accident at the CSB is $(24) \times\left(3.52 \times 10^{-11}\right)=8.45 \times 10^{-10}$. Therefore the thermal runaway accident at the CSB is considered to be an incredible event.

Uncertainty was estimated on the solution of the fault tree. The estimate was based on 5,000 samples, mean values for failure probabilities, log normal distribution assumptions for the failure probability distribution, and an error factor of 10 for all failure probabilities except errors with a probability of one. The estimate show an uncertainty band between $4.54 \times 10^{-13}$ and $1.24 \times 10^{-10}$, based on $5 \%$ and $95 \%$ respectively. 


\subsection{CONCLUSIONS}

The thermal runaway accident is considered an incredible event for the following reasons.

- There is not sufficient water in an MCO to produce a continuing reaction.

- Cooling at the sampling/weld station will not be lost for a period longer than 50 days.

- The MCO will not stay at the sampling/weld station for more than 50 days.

- The chance for a complete shear of the MCO is incredible. 
SNF-4042 REV 0

This page intentionally left blank. 


\subsection{FREQUENCY OF VIOLATION OF DESIGN TEMPERATURE CRITERIA}

\subsection{INTRODUCTION}

Heat is produced in the MCO from energy released by radioactive decay and energy released from chemical reactions that occur between the fuel and water or gases. The MCO and CSB have been designed to provide for ample heat transfer away from the MCO so that an unacceptably high temperature will not be reached during normal handling and storage of the MCOs at the CSB. This analysis estimates the frequency of an event that may lead to a violation of the MCO design temperature criteria.

\subsection{PROBABILITY ESTIMATES}

A logic diagram, in fault tree format, was constructed (Figure 7) to assess the likelihood of exceeding MCO design temperature criteria. Each box with a circle underneath represents a failure that could contribute to a potential MCO shear. The failures are combined through logic gates: AND gates (flat bottom, semicircle top) or OR gates (arched bottom and arrowhead top). An AND gate requires all inputs to the gate (from below) to occur for the result, described in the box above the gate, to occur. An OR gate only requires that any one input to the gate (from below) occur for the result, described in the box above the gate, to occur. Final estimates of the total likelihood of exceeding $\mathrm{MCO}$ design temperature criteria are obtained by properly combining the probabilities of each branch of the diagram according to Boolean algebra. The following text describes each event for each path of the logic fault tree. The descriptions include estimates used in the current analysis of the probability for each event to occur.

\subsubsection{Loss of Active Cooling in Sampling/Weld Station Pit}

Failure Event V201. Twenty-four MCOs per year will be sampled. Each MCO will stay at the sampling/weld station for 6 hours. The probability of having one $\mathrm{MCO}$ is at the sampling/weld station is $(24) \times(6 / 8,760)=1.64 \times 10^{-2}$.

Failure Event V202. The glycol cooling system installed in the sampling/weld station pit is capable of removing heat from the MCO. The failure rate (fail to run) for air conditioning units is $3.0 \times 10^{-5}$ per hour (EGG-SSRE-8875). It is conservatively assumed that the probability of failure is $1.0 \times 10^{-4}$ per hour $\left(8.8 \times 10^{-1}\right.$ in 8,760 hours $)$.

Failure Event V203. Calculations indicate that for a maximum heat generation MCO, it is possible to exceed the $M C O$ temperature design criteria in about 50 days without active cooling (HNF-3553, Annex A). For the temperature criteria to be exceeded, the MCO would have to be located in the sampling/weld station pit for about 2 months or more without cooling. It is highly unlikely that the cooling unit would not be restored for 2 months. The probability of failure to resume active cooling within 50 days is assumed to be $1.0 \times 10^{-4}$. 
Failure Event V204. The MCO should be removed from the sampling/weld station pit after an extended period of time without active cooling. The probability that the MHM is unable to remove the $\mathrm{MCO}$ from the sampling/weld station pit within 2 months is assumed to be $1.0 \times 10^{-3}$ because of a failure of the MHM and a failure to restore MHM operation within 2 months. This is judged to be a conservative estimate of the combined probability of both MHM failure and failure to restore MHM operation.

Failure Event V101. Failure events V201, V202, V203, and V204 must all be true for the $\mathrm{MCO}$ design temperature criteria to be exceeded. Combining the probabilities of failure events V201, V202, V203, and V204, the probability that the MCO temperature design criteria are exceeded is $\left(1.64 \times 10^{-2}\right) \times\left(8.76 \times 10^{-1}\right) \times\left(1.0 \times 10^{-4}\right) \times\left(1.0 \times 10^{-3}\right)=\left(1.44 \times 10^{-9}\right)$.

\subsubsection{Loss of Passive Cooling in Vault}

Failure Event V301. If the vault intake and/or exhaust stacks are partially or fully blocked, natural convection of air through the vault will be reduced. If $50 \%$ or less of the inlet area were blocked, it is expected that the vault air flow rate and $\mathrm{MCO}$ and ceiling temperatures would be nearly equal to those expected for zero blockage (HNF-3553, Annex A). It is conceivable that over a long period of time some debris could accumulate over the opening or pass through the outer grating and accumulate on the inner horizontal grating. Because the opening in the vertical inlet grating has a total flow area that is more than six times that of the horizontal cross section of the inlet, about $92 \%$ of the vertical grating area must become fully blocked before more than $50 \%$ of the inlet cross-sectional area will be blocked. Given that such a large percentage of the four-sided vertical inlet must become fully blocked and that this inlet is located at a great height above the existing grade, the probability that the block is more than $50 \%$ of the inlet cross-sectional area is assumed to be very small (i.e., $1.0 \times 10^{-5}$ ).

Failure Event V302. It is prudent to have an infrequent but regular program to visually inspect the inlet for blockage. The probability of failure of the program is assumed to be $3.0 \times 10^{-2}$, which is based on the basic human error probability.

Failure Event V206. If failure events V301 and V302 are both true, the vault intake stack is more than $50 \%$ blocked. Combining the probabilities of failure events V301 and V302, the probability that the intake is blocked by more than $50 \%$ is $\left(1.0 \times 10^{-5}\right) \times\left(3.0 \times 10^{-2}\right)$ $=3.0 \times 10^{-7}$.

Failure Event V205. If the vault inlet stack were somehow completely blocked, the MCO wall temperature would reach the $270^{\circ} \mathrm{F}$ CSB limit in about 15 hours and would continue to rise. The probability that the temperature rise is not noticed within 15 hours is assumed to be one.

Failure Event V102. If failure events V205 and V206 are both true, the MCO may exceed the temperature design criteria. Combining the probabilities of failure events V205 and V206, the probability that the MCO may exceed the temperature design criteria is $3.0 \times 10^{-7}$. 


\subsubsection{Top Event}

The MCO may exceed the temperature design criteria either because of a loss of active cooling or a blockage of the intake. The frequency of occurrence is estimated as $\left(1.44 \times 10^{-9}\right)$ $+\left(3.0 \times 10^{-7}\right)=3.0 \times 10^{-7}$.

Uncertainty was estimated on the solution of the fault tree. The estimate was based on 5,000 samples, mean values for failure probabilities, log normal distribution assumptions for the failure probability distribution, and an error factor of 10 for all failure probabilities except errors with a probability of one. The estimate show an uncertainty band between $2.02 \times 10^{-9}$ and $1.07 \times 10^{-6}$, based on $5 \%$ and $95 \%$ respectively.

\subsection{CONCLUSIONS}

It is estimated that the event that has the potential of violating the MCO temperature design criteria is an incredible event. 
SNF-4042 REV 0

This page intentionally left blank. 


\section{SNF-4042 REV 0}

\subsection{REFERENCES}

DP-1633, 1982, Component Failure-Rate Data With Potential Applicability To A Nuclear Fuel Reprocessing Plant, E.I. du Pont de Nemours \& Co. Savannah River Laboratory, Aiken, South Carolina.

EGG-SSRE-8875, 1990, Generic Component Failure Data Base for Light Water and Liquid Sodium Reactor PRAs, EG\&G, Idaho Falls, Idaho.

H-2-123400, Operational Sequence Block Flow Diagram Validation MCO Operations, Sheet 7 , Rev. F, Fluor Daniel Hanford, Incorporated, Richland, Washington.

HNF-3553, 1999, Spent Nuclear Fuel Project Final Safety Analysis Report, Annex A, "Canister Storage Building Final Safety Analysis Report," Rev. 0, Fluor Daniel Hanford, Incorporated, Richland, Washington.

HNF-SD-SNF-HIE-001, 1999, Canister Storage Building Hazard Analysis Report, Rev. 1, Fluor Daniel Hanford, Incorporated, Richland, Washington.

NUREG/CR-4772, 1987, Accident Sequence Evaluation Program Human Reliability Analysis Procedure, U.S. Nuclear Regulatory Commission, Washington, D.C.

Sellers, E. D., 1997, Risk Evaluation Guidelines (REGs) to Ensure Inherently Safer Designs, (Letter 97-SFD-172 to H. J. Hatch, Fluor Daniel Hanford, Incorporated, August 26), U.S. Department of Energy, Richland Operations Office, Richland, Washington.

SNF-4087, 1999, Evaluation to Determine the Frequency of a Multi-Canister Overpack Drop from the Multi-Canister Overpack Handling Machine at the Canister Storage Building, Rev. 0, Fluor Daniel Hanford, Incorporated, Richland, Washington.

WHC-EP-0811, 1995, Analysis of Power Loss Data for the 200 Area Tank Farms in Support of $K$ Basin SAR Work, Westinghouse Hanford Company, Richland, Washington.

WHC-SD-W236A-TI-002, 1996, Probabilistic Seismic Hazard Analysis, DOE Hanford Site, Washington, Rev. 1, Prepared by Geomatrix Consultants, Incorporated, for Westinghouse Hanford Company, Richland, Washington. 
SNF-4042 REV 0

This page intentionally left blank. 


\subsection{PEER REVIEW CHECKLIST}

\section{PEER REVIEW CHECKLIST}

\section{Document Title: $\quad$ SNF-4042, Evaluation of Accident Frequencies at the Canister Storage Building}

Document Author: Justin Liu

Document Date:

Scope of Review: Reviewed for adequacy of frequency assumptions, data usage, and hand calculations.

\section{Yes No NA}

[] [] [X]

[X] [] []

[X] [] []

[X] [] []

[] [] $[\mathrm{X}]$

[X] [] []

[X] [] []

[X] [] []

[X] [ ] [ ]

[X] [] []

[] [] $[\mathrm{X}]$

[] [] [X]

$[\mathrm{X}] \mathrm{[}] \quad[]$

[X] [ ] [ ]

[X] [] [ ]

[X] [ ] [ ]

[] [] [X]

[ ] $\left[\begin{array}{ll}{[} & {[\mathrm{X}]}\end{array}\right.$
Previous reviews complete and cover analysis, up to scope of this review, with no gaps.

Problem completely defined.

Accident scenarios developed in a clear and logical manner.

Necessary assumptions explicitly stated and supported.

Computer codes and data files documented.

Data used in calculations explicitly stated in document.

Data checked for consistency with original source information as applicable.

Mathematical derivations checked including dimensional consistency of results.

Models appropriate and used within range of validity or use outside range of established validity justified.

Hand calculations checked for errors. Spreadsheet results should be treated exactly the same as hand calculations.

Software input correct and consistent with document reviewed.

Software output consistent with input and with results reported in document reviewed.

Limits/criteria/guidelines applied to analysis results are appropriate and referenced. Limits/criteria/guidelines checked against references.

Safety margins consistent with good engineering practices.

Conclusions consistent with analytical results and applicable limits.

Results and conclusions address all points required in the problem statement.

Format consistent with appropriate NRC Regulatory Guide or other standards Review calculations, comments, and/or notes are attached.

\section{[X] [ ] [ [ Document approved.}

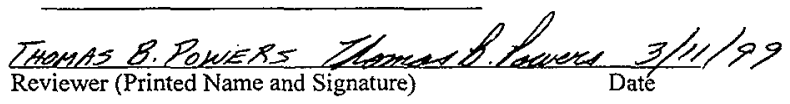


SNF-4042 REV 0

This page intentionally left blank. 
Figure 1. Fault Tree for a Shear of a Multi-Canister Overpack by the Multi-Canister Overpack Handling Machine at the Canister Storage Building. (sheet 1 of 6 )

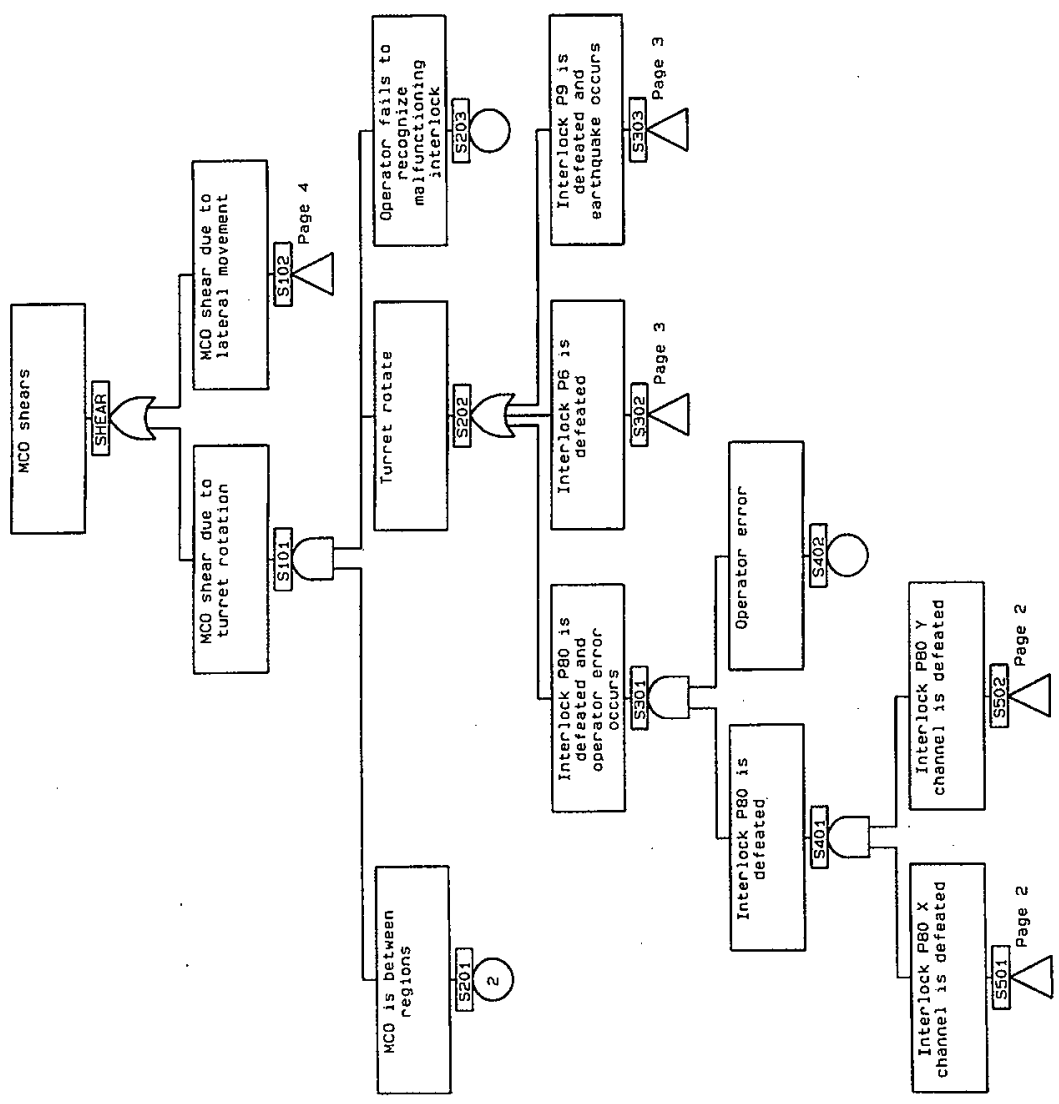


Figure 1. Fault Tree for a Shear of a Multi-Canister Overpack by the Multi-Canister Overpack Handling Machine at the Canister Storage Building. (sheet 2 of 6)

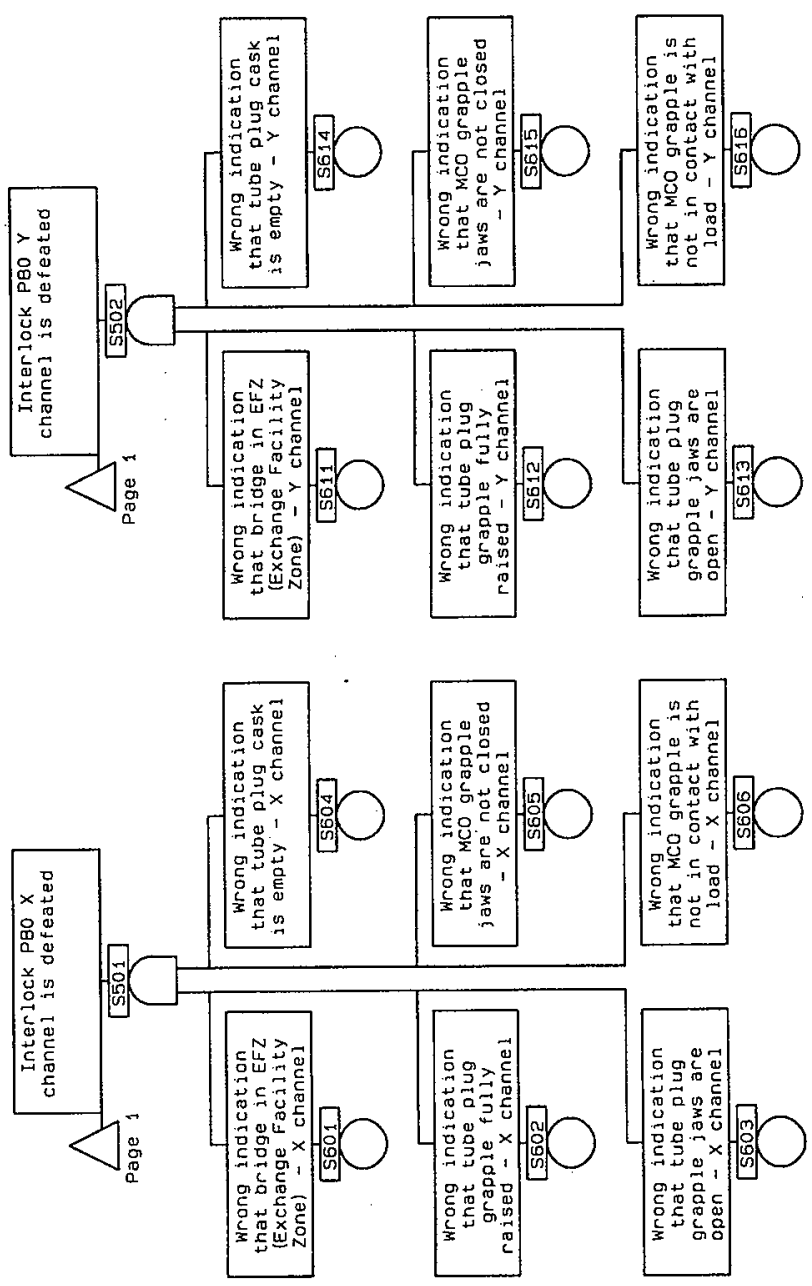


Figure 1. Fault Tree for a Shear of a Multi-Canister Overpack by the Multi-Canister Overpack Handling Machine at the Canister Storage Building. (sheet 3 of 6)
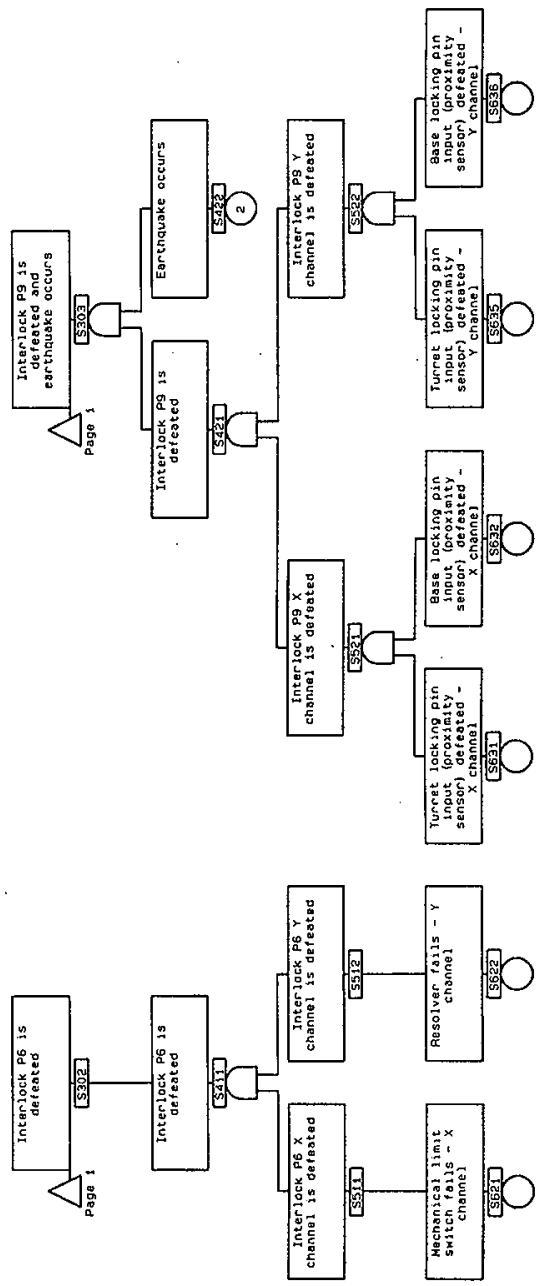
Figure 1. Fault Tree for a Shear of a Multi-Canister Overpack by the Multi-Canister Overpack Handling Machine at the Canister Storage Building. (sheet 4 of 6)

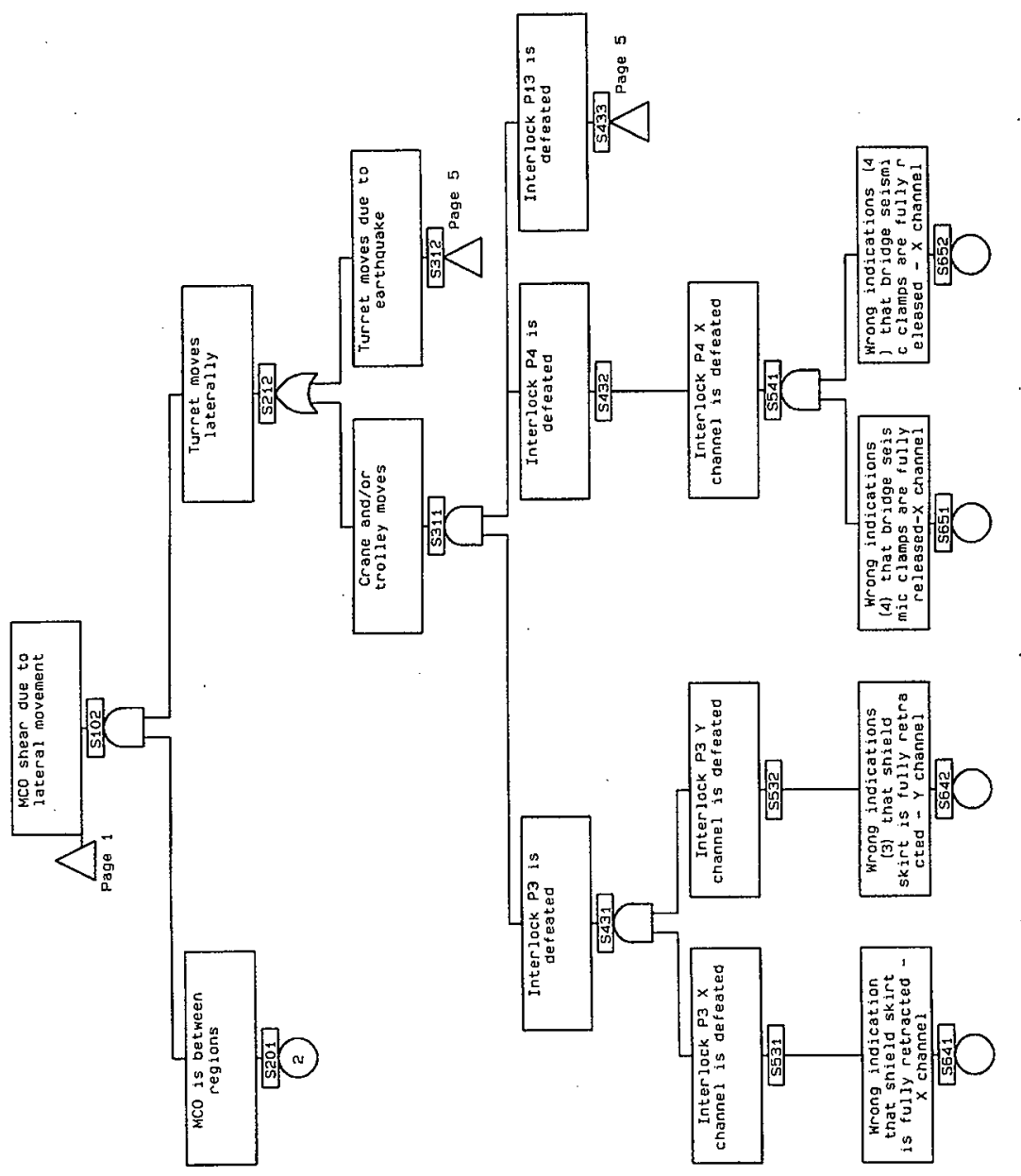


Figure 1. Fault Tree for a Shear of a Multi-Canister Overpack by the Multi-Canister Overpack Handling Machine at the Canister Storage Building. (sheet 5 of 6 )
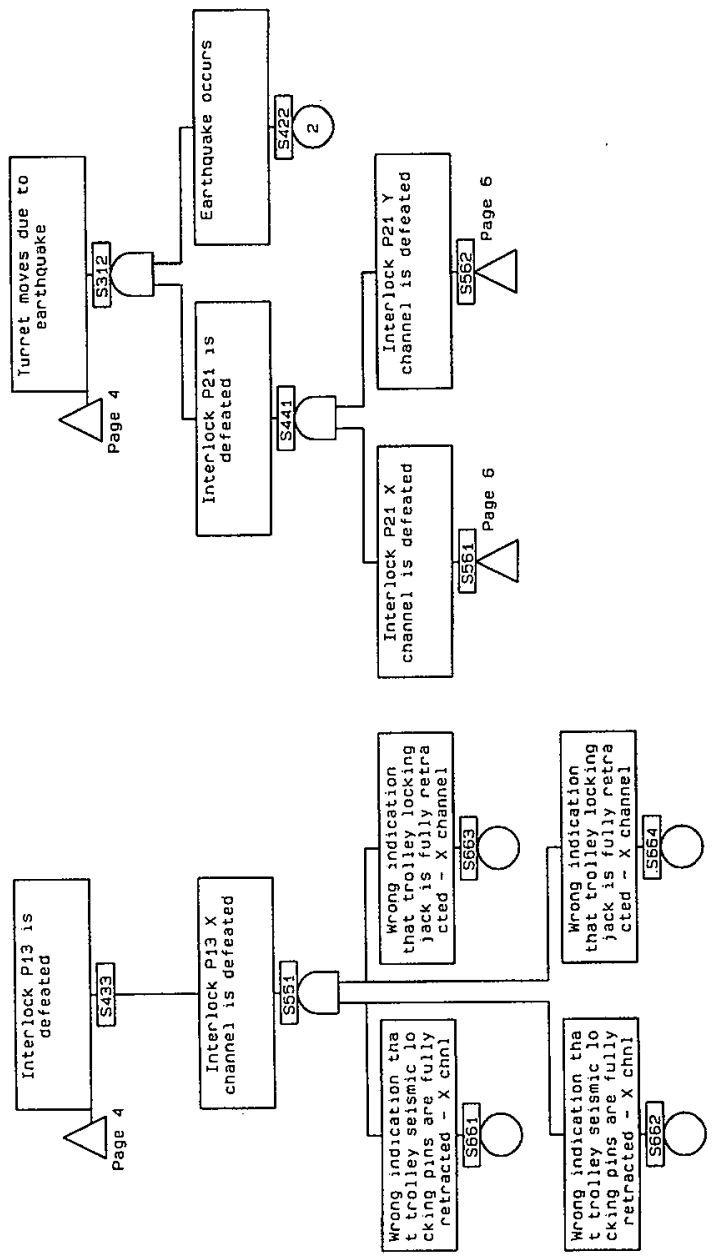
Figure 1. Fault Tree for a Shear of a Multi-Canister Overpack by the Multi-Canister Overpack Handling Machine at the Canister Storage Building. (sheet 6 of 6 )
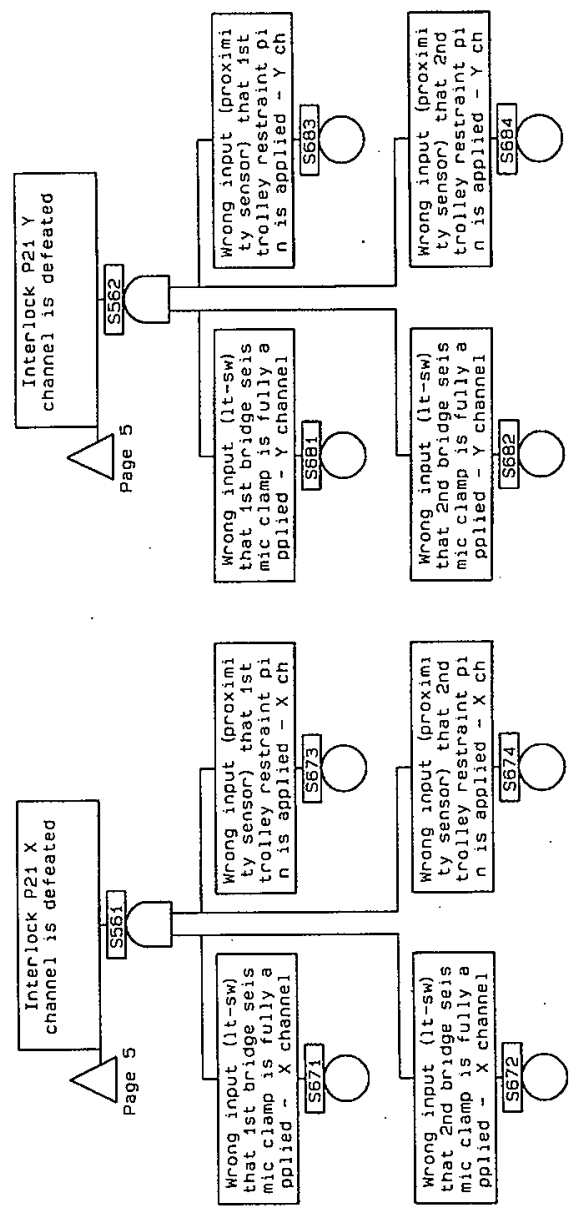
Figure 2. Fault Tree for Overpressurization of the Multi-Canister Overpack by the Inert Gas System.

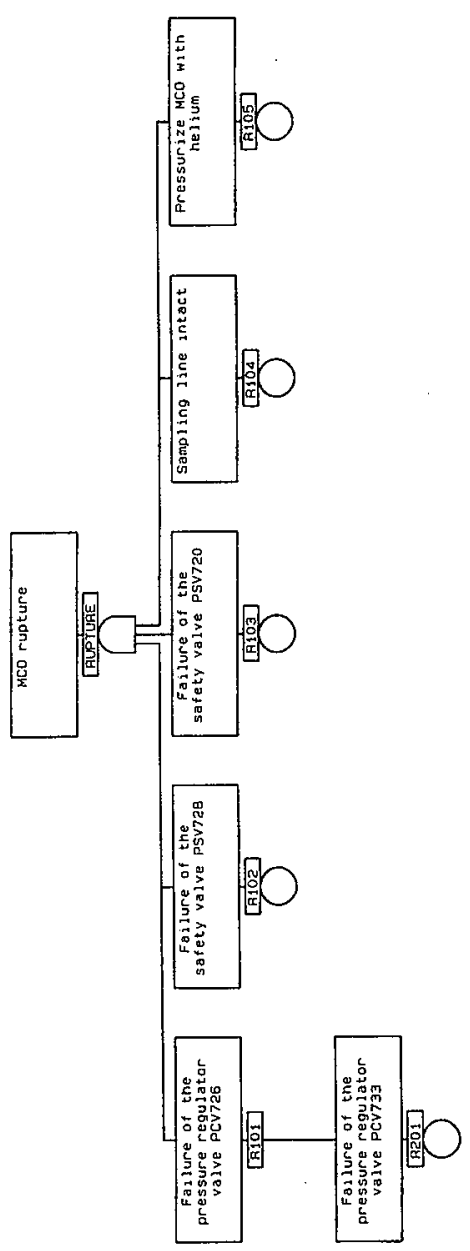


Figure 3. Fault Tree for a Gaseous Release Resulting from a Leak in the Multi-Canister Overpack Sampling System at the Canister Storage Building. (sheet 1 of 2)

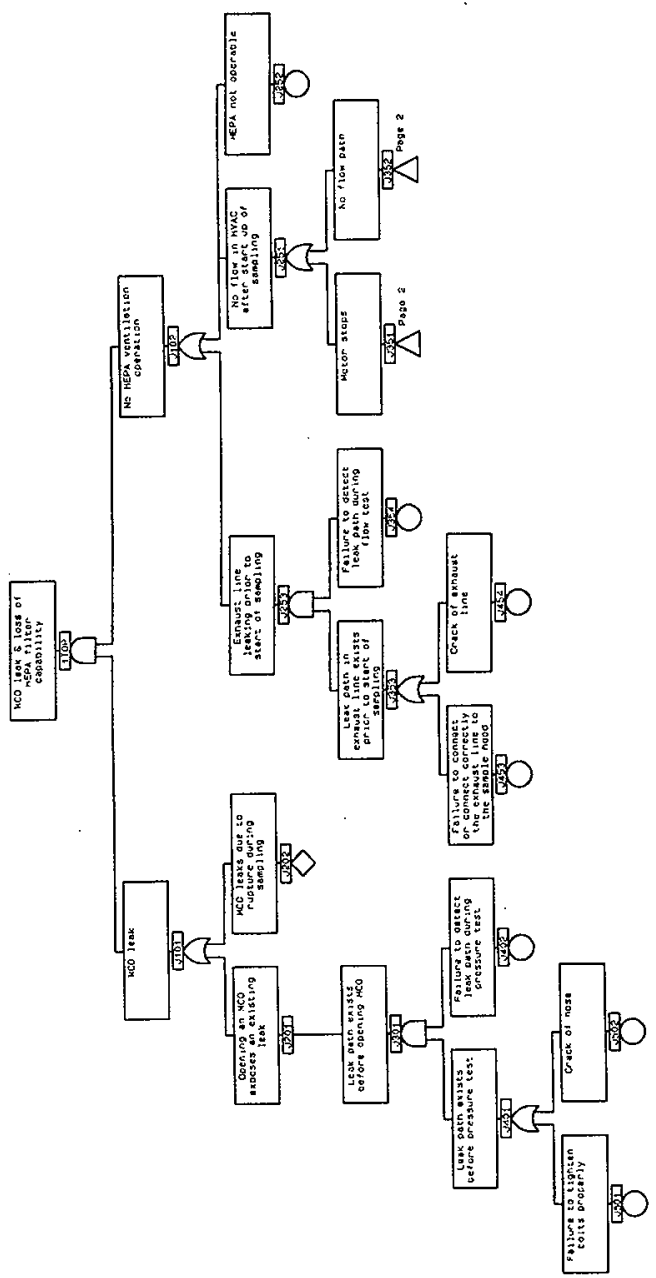


Figure 3. Fault Tree for a Gaseous Release Resulting from a Leak in the Multi-Canister Overpack Sampling System at the Canister Storage Building. (sheet 2 of 2)

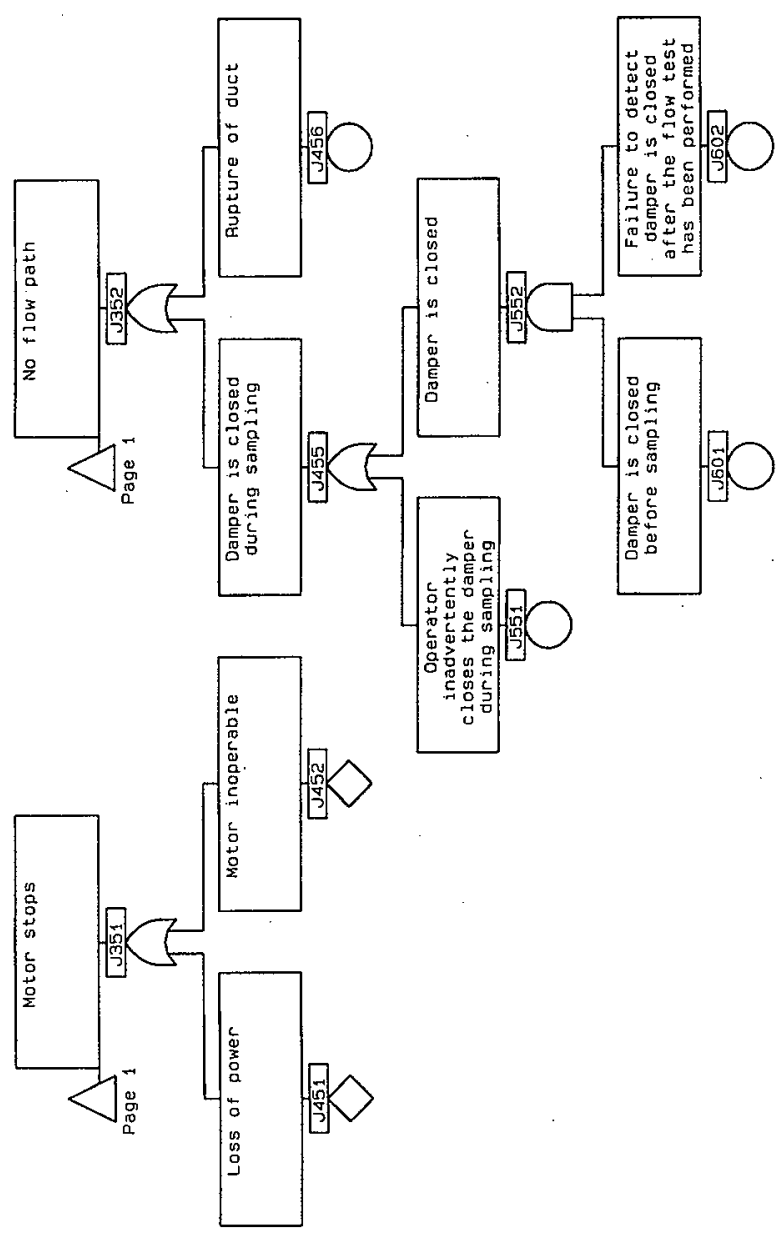


Figure 4. Fault Tree for a Multi-Canister Overpack Internal Explosion at the Canister Storage Building.

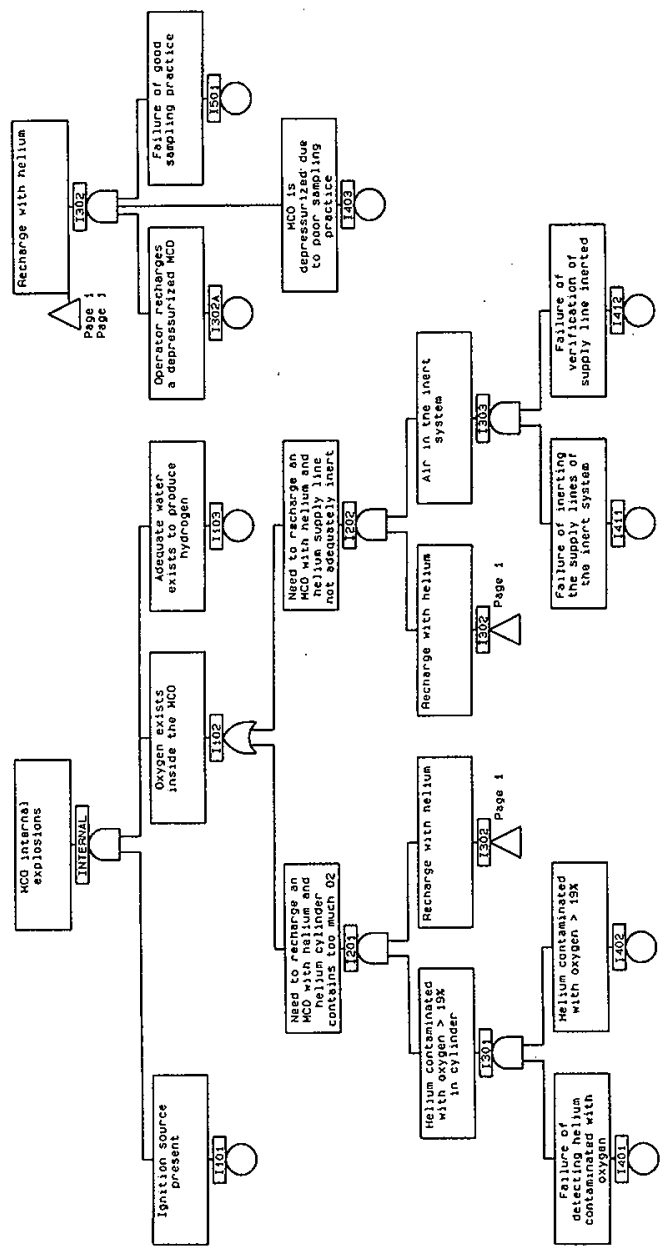


Figure 5. Fault Tree for a Multi-Canister Overpack External Explosion at the Canister Storage Building.

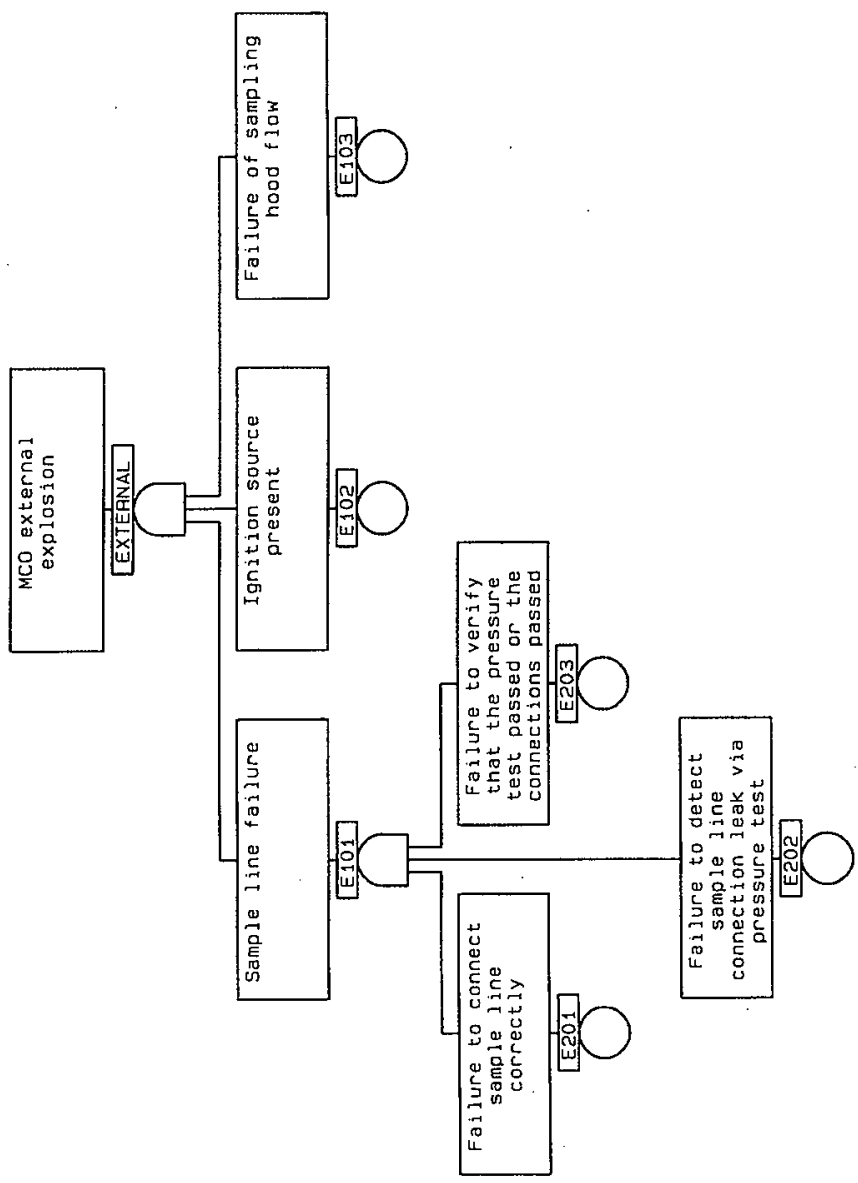


Figure 6. Fault Tree for a Thermal Runaway Accident in a Multi-Canister Overpack at the Canister Storage Building.

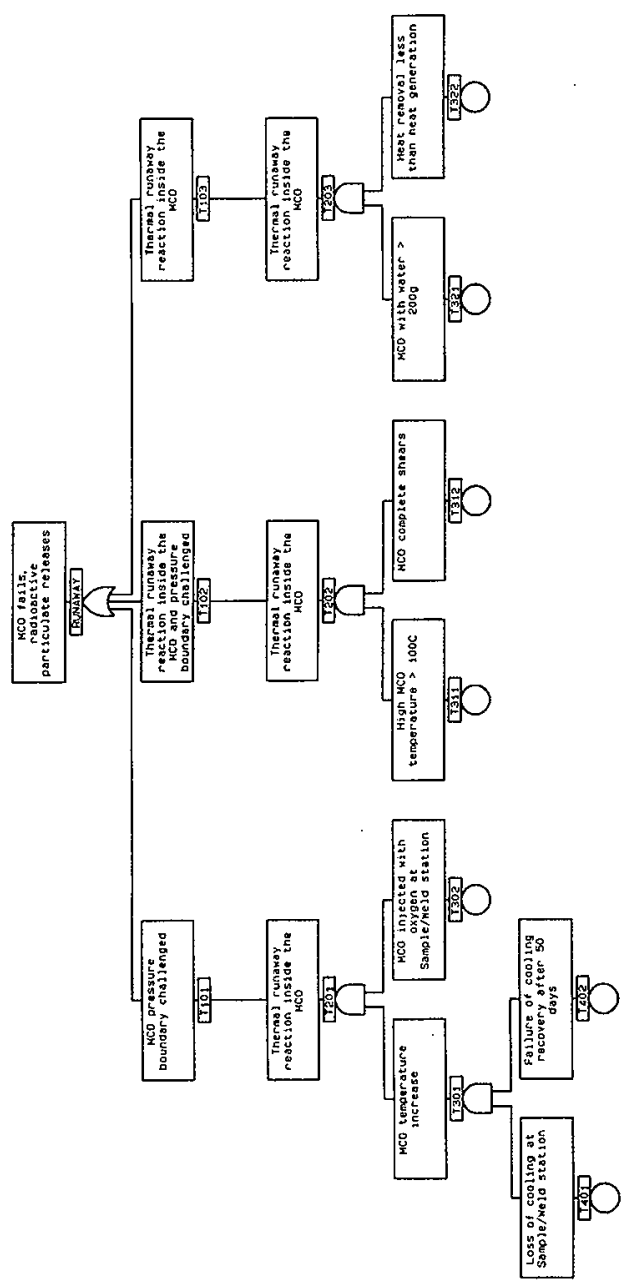


Figure 7. Fault Tree for Violation of Design Temperature Criteria.

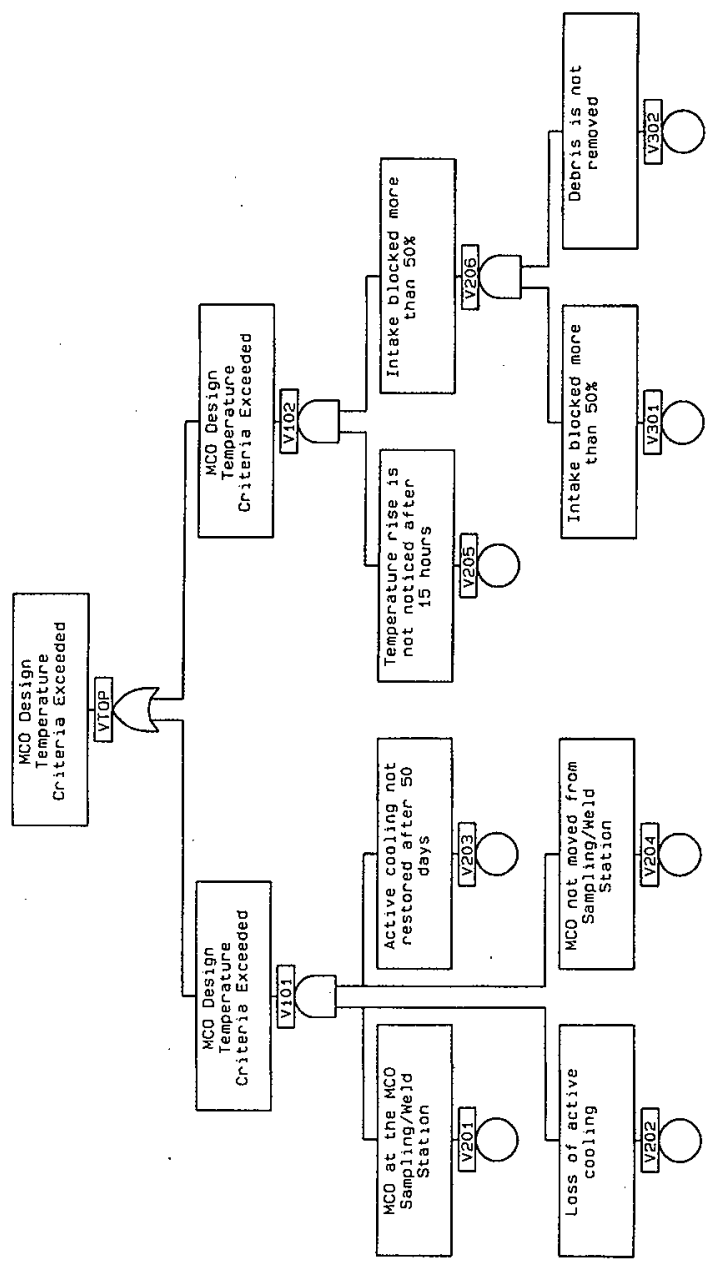


SNF-4042 REV 0

This page intentionally left blank. 